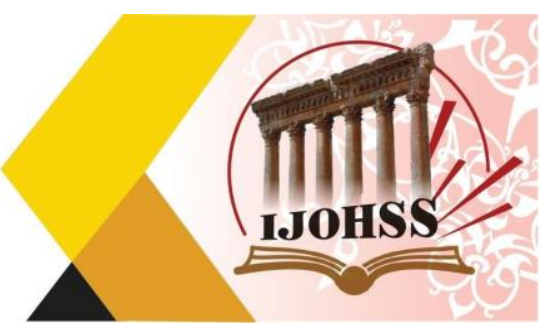

\title{
التجارب الدولية في التعليم في ظل جائحة كورونا
}

\author{
دوز مرزوق بن مطر الفهمي \\ دكتوراه في الإدارة التربوية و التخطيط \\ البريد الاكتروني: mmalfahmy@gmail.com
}

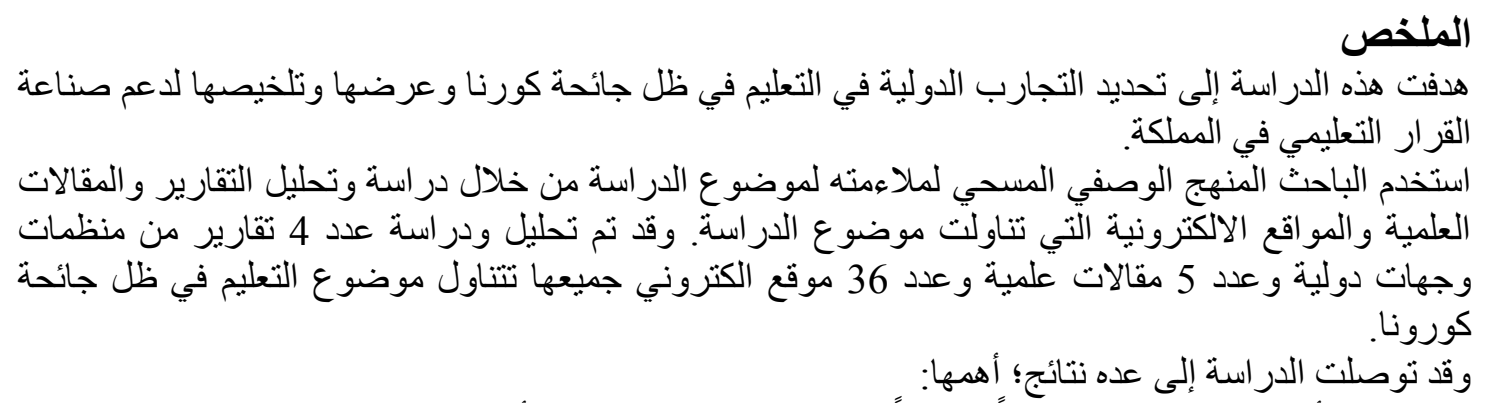
1- يجب أن يتبنى قادة التعليم نهجاً استباقياً للمساهمة في التخفيف من تأثير الوباء ومنع فقدان التعلم خلال فترة التباعد الاجتماعي الضرورية.

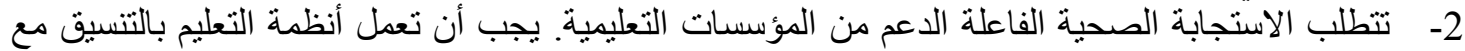

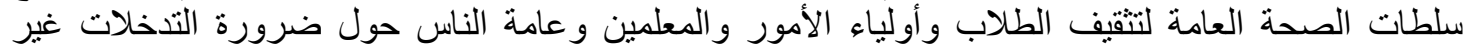

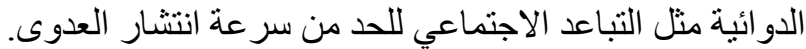
3- يجب أن تحد استر اتيجيةٌ التعليم الجديدة من فقدان التعلم الناتج عن التدخلات غير الدوائية للتخفيف من تأثير الوباء. 4- - في المرتبة الثانية بعد دعم التعلم، يجب أن تكون مصلحة الطلاب و الموظفين أولوية رئيسة للمؤسسات

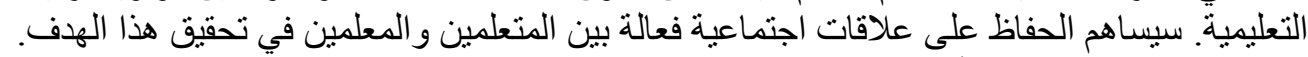

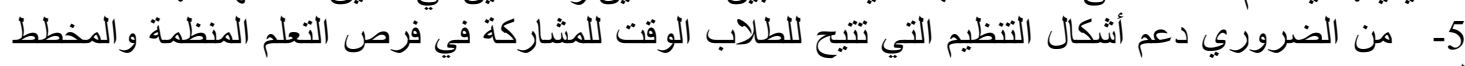

وفي ظل نتائج الدر اسة السابقة توصل الباحث إلى عدد من التوصيات؛ ومن أهن أهمها:

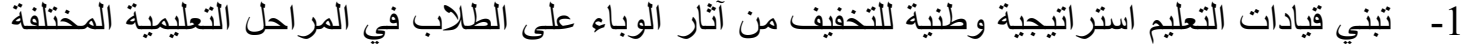
خاصة المر احل الدنيا في التعليم. 2- التخفيف من المركزية في تقديم التهائ التعليم عن بعد ومنح صلاحيات و اسعة للإدارات التعليمية لتقديم التعليم عن بعد وفق إمكاناتها. الكلمات المفتاحية : جائحة كورونا، التعليم. 


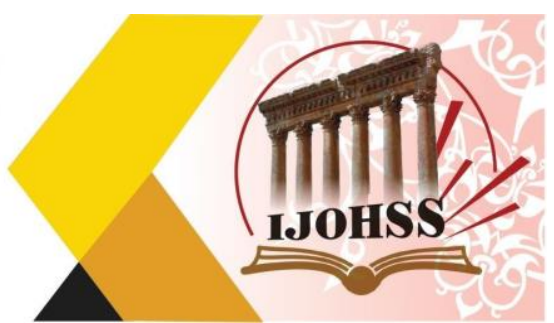

\title{
International experiences in education in light of the Corona pandemic
}

\author{
Dr. Marzouq Matar Al-Fahmi \\ PhD in Educational Administration and Planning \\ Email: mmalfahmy@gmail.com
}

\begin{abstract}
This study aimed to identify international experiences in education in the light of the Corona pandemic, and present and summarize them to support educational decisionmaking in the Kingdom.
\end{abstract}

The researcher used the descriptive survey approach to its relevance to the subject of the study through studying and analyzing reports, scientific articles and websites that dealt with the subject of the study. The analysis and study of 4 reports from international organizations and bodies, 5 scientific articles and 36 websites all analyzed the topic of education in light of the Corona pandemic.

The study reached several results. The most important of them are: 1- Education leaders must adopt a proactive approach to contribute to mitigating the impact of the epidemic and preventing learning loss during the necessary social spacing.

2- An effective health response requires support from educational institutions. Education systems should work in coordination with public health authorities to educate students, parents, teachers, and the general public about the necessity of nondrug interventions such as social divergence to reduce the speed of infection.

3- The new education strategy must reduce the learning loss caused by non-drug interventions to mitigate the impact of the epidemic.

4- In the second place after supporting learning, the interest of students and employees should be a major priority for educational institutions. Maintaining effective social relationships between learners and teachers will contribute to this goal.

5- It is necessary to support forms of organization that allow students time to participate in organized and planned learning opportunities.

In light of the results of the previous study, the researcher reached a number of recommendations. and the most important:

1- Education leaders adopt a national strategy to mitigate the effects of the epidemic on students at different educational levels, especially the lower levels of education.

2- Reducing the centralization in providing distance education and granting wide powers to educational departments to provide distance education according to its capabilities.

Keywords: Corona pandemic, education. 


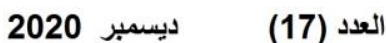

ISSN: 2415 - 4822

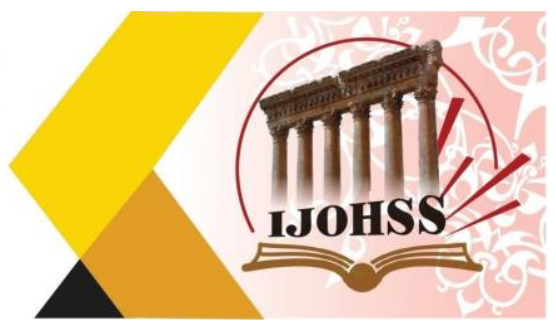

مقدمه:

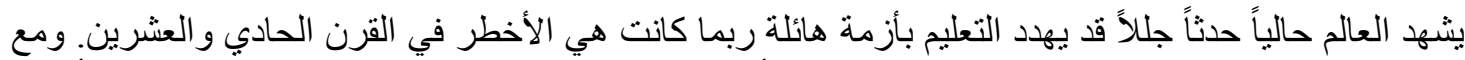

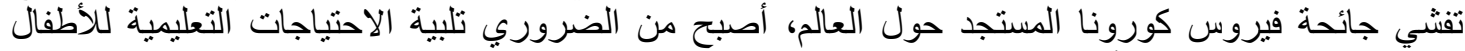

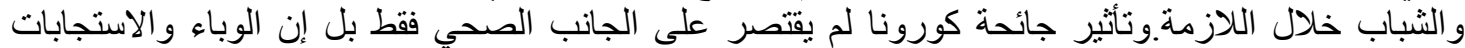

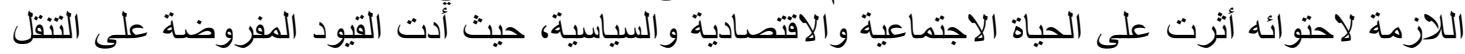

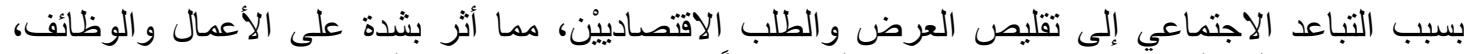

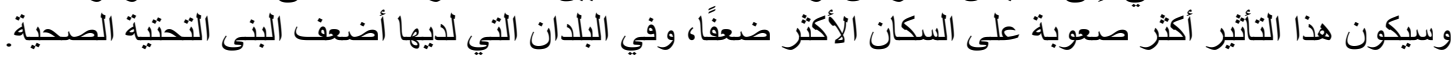

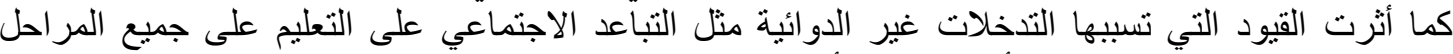

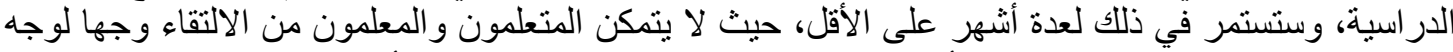

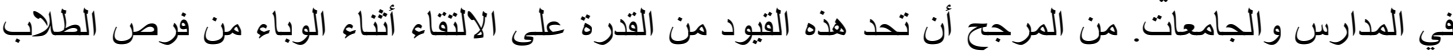

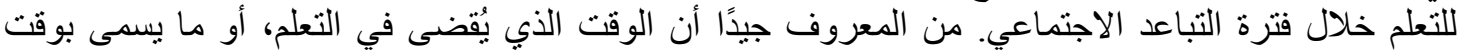

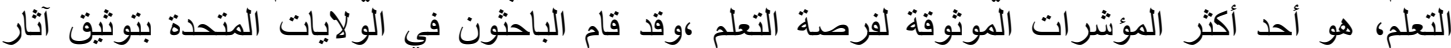

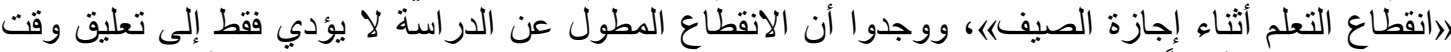

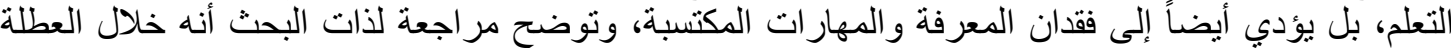

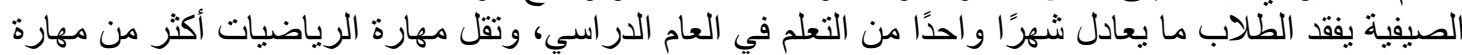

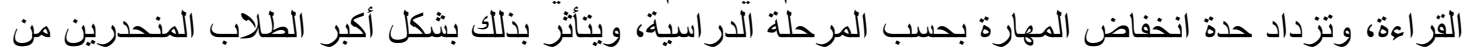

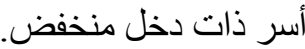

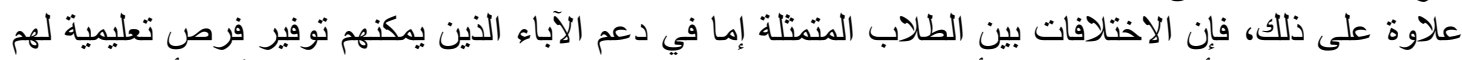

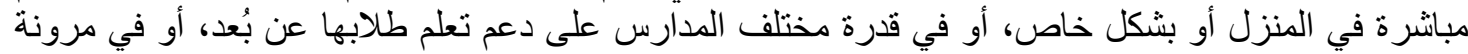

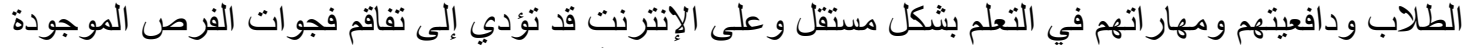

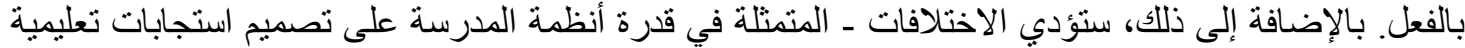

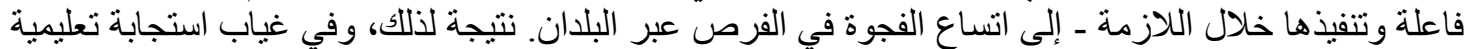

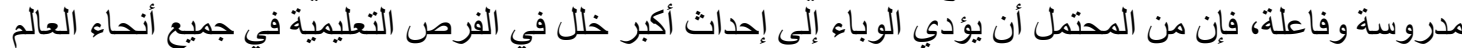
خلال جيل و احد، ومما لا شك فيه فيه أن ذللك سينعكس على سلى سبل عيش الأفر اد و آفاق مجتمعاتهم.

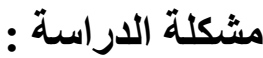

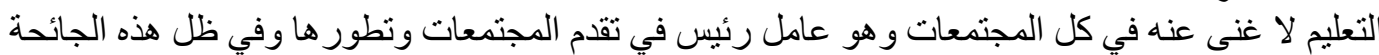

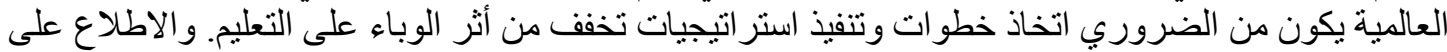

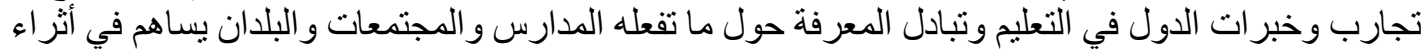

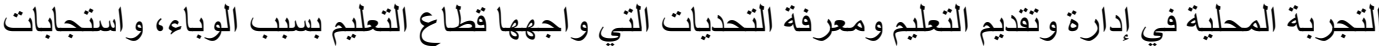

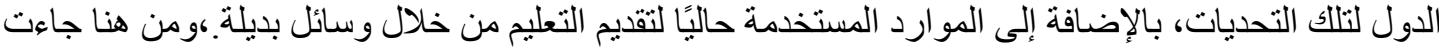
هذه الدر اسة للإجابة على التساؤل الرئيسي: ماهي أبرز التجارب والئي الممارسات العالمية في التعليم في ظل جائحة

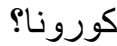

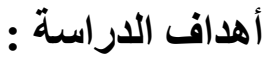

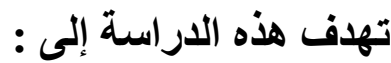
1- - تحديد أبرز التجارب الدولية في التعليم خلال جائحة كورونا و عرضها بصورة .

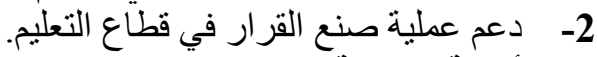

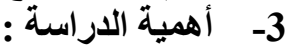

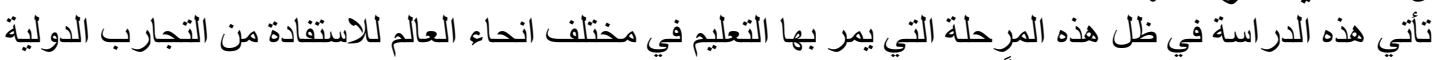

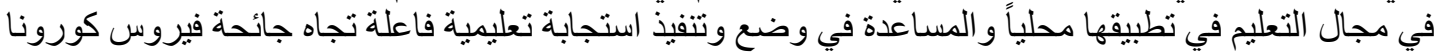




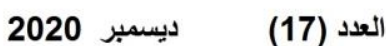

ISSN: $2415-4822$
Volume (17) December 2020

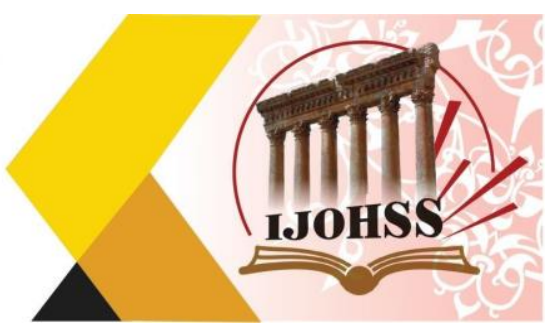

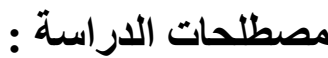

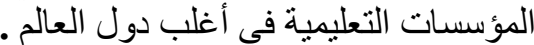
التجارب الدولية: هي ممارسات الدول في الدي مختلف انحاء العالم في مجال التعليم في ظل جائحة كورونا

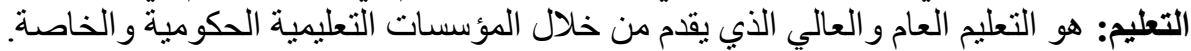

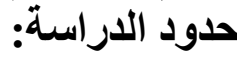
الحد الموضوعي: التجارب الدولية في التعليم في ظل جائحة كورونا الحد المكاني : المملكة العربية السعودية الرية العية

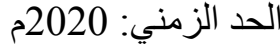

\section{الإطار النظري}

\section{برز التجارب والمبادرات العالمية لتمكين استمرار التعليم:}

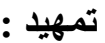

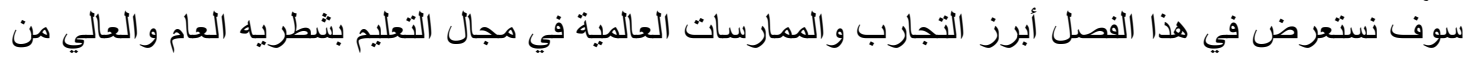

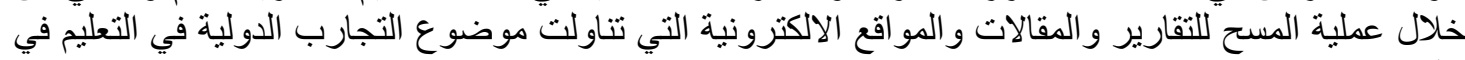
ظل جل جائحة كورنا.

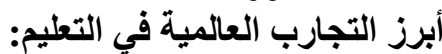
استراليا: تم تشجيع التعلم عن بُعد عبر الإنترنت من خلال التعلم التعلم المهني. تستخدم كل مدرسة أنظمة أساسية

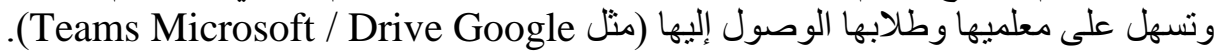
بلجيكا: تم بث البر امج التعليمية من خلال التلفزيون القومي للتنأكيد على أهمية مواصلة التهلة التعليم المنزلي.

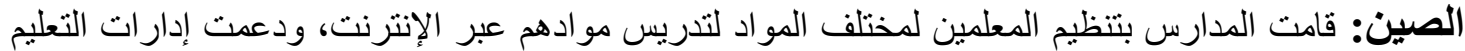

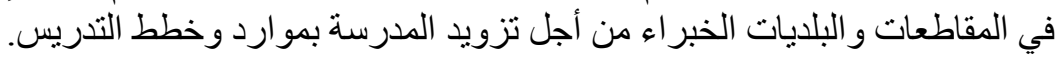

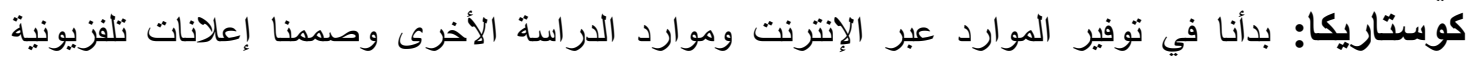

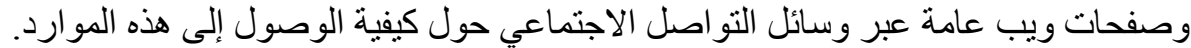
جمهورية التشيك: أطلقت الوزارة موقعًا إلكترونيًا الإنترنت. إستونيا: تقدم وزارة التعليم والبحوث الدعم و المبادئ التوجيهية اليومية لجميع المؤسسات التعليمية، بما في ذلك المنظمات الثبابية (مدارس الهوايات، ومر اكز الثرات الثباب المفتوحة) https://www.hm.ee/et/koroonaviiruse-leviku-tokestamine-infoharidusasutustele

$$
\text { بالإضافة إلى ذلك تقدم مؤسسة Innove: }
$$
https://www.innove.ee/uudis/info-ja-nouandedvanematele-oma-lapse-toetamiseks-COVID19-pandeemia-ajal/

(https://www.hitsa.ee/eope-korduma-kippuvad-kusimused)

$$
\text { ومؤسسة تكنولوجيا المعلومات للتعليم: }
$$

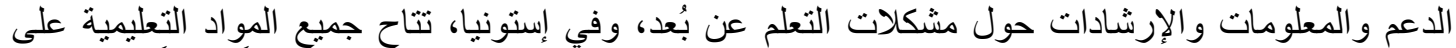

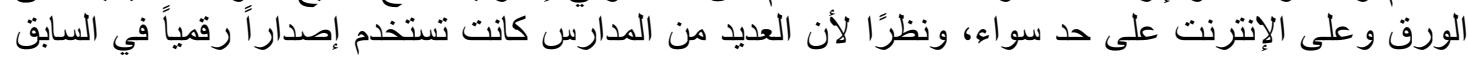

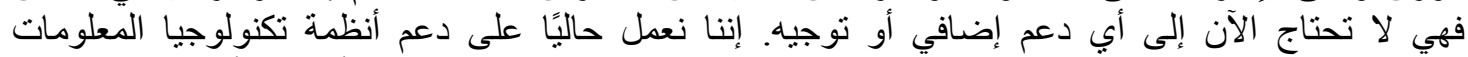

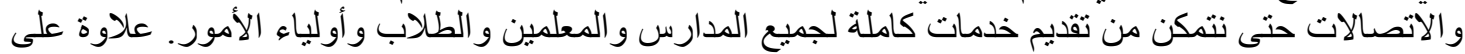

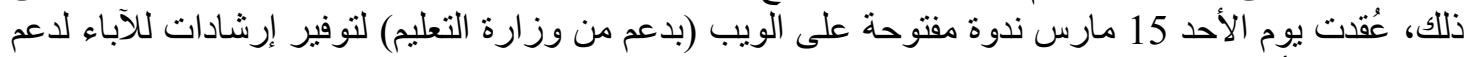

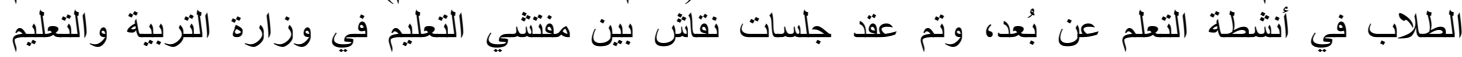




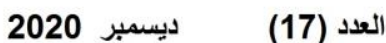

ISSN: 2415 - 4822

\section{Volume (17) December 2020}

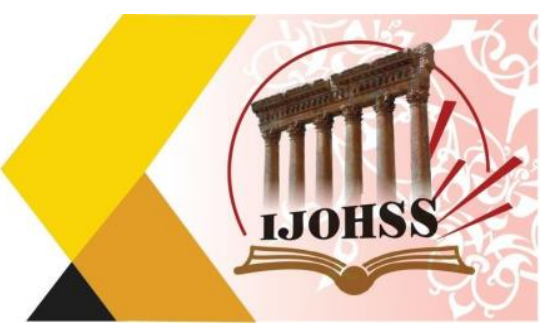

و المتخصصين النربويين بالسلطة المحلية لإظهار الدعم وتحديد أفضل الممارسات والمشكلات التي يو اجهونها،

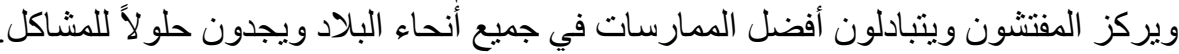

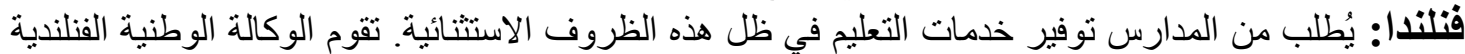

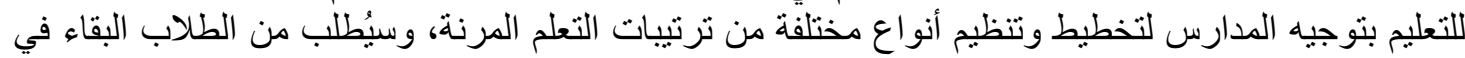

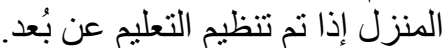

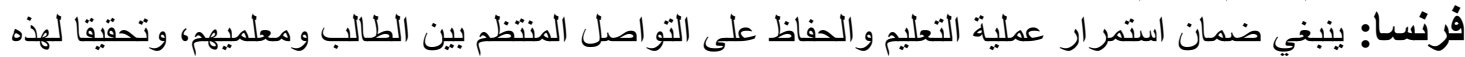

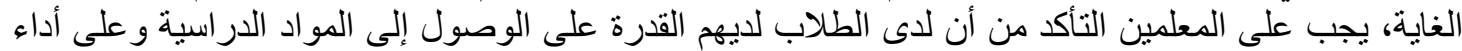

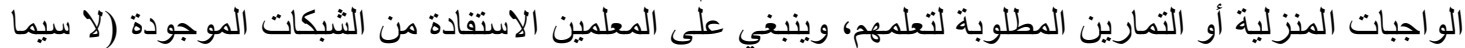

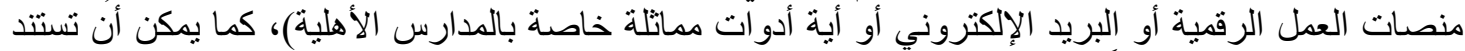

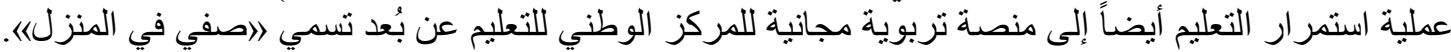

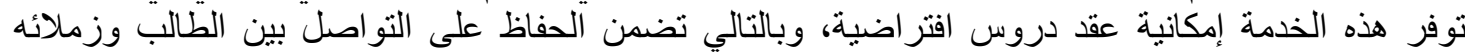

ومعلميا.

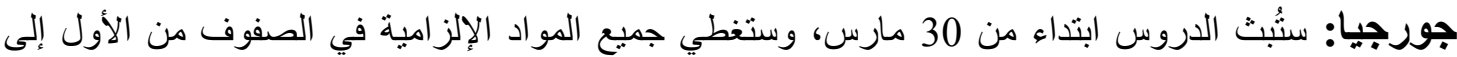

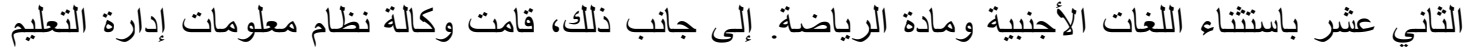
التابعة لوزارة التربية و التعليم بالأنشطة التالية:

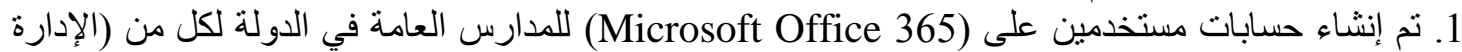

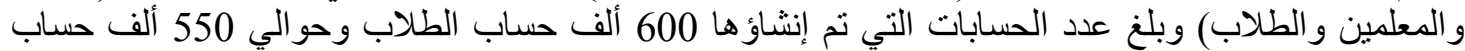
للمعلمين. 2. تم إنثاء بو ابة تسمح للطالب وأولياء الأمور بالوصول إلى ملف تعريف الطالب.

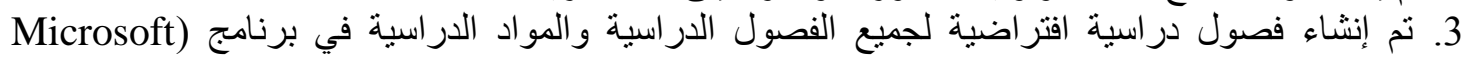
(TEAMS

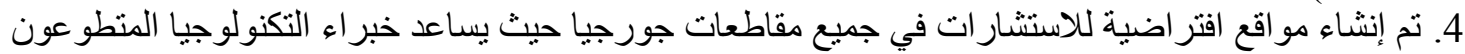

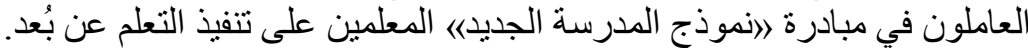

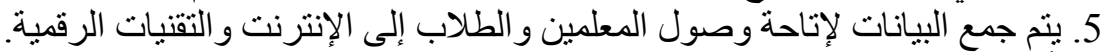

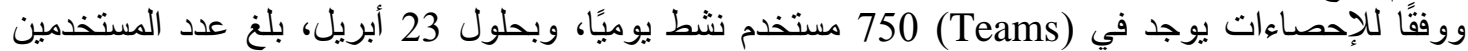

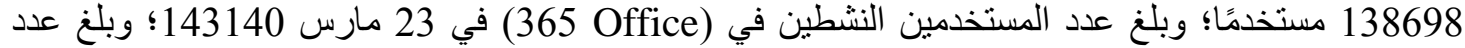

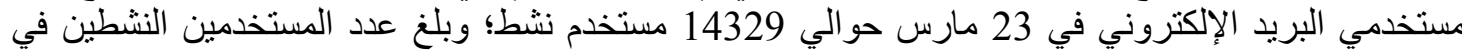
OneDrive)

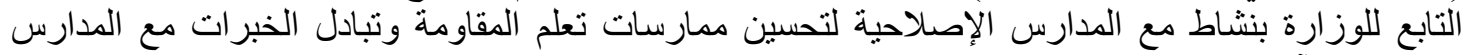

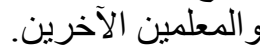

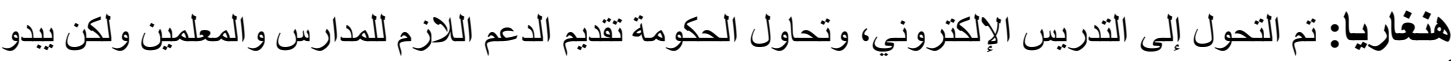

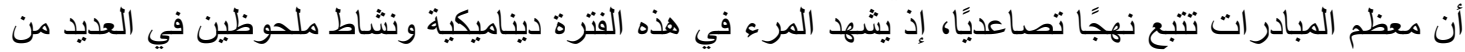
المدارس.

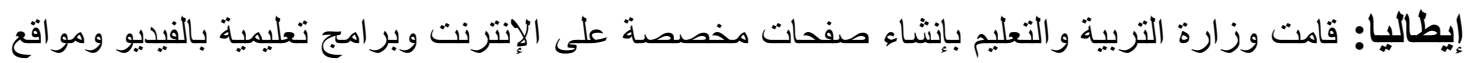

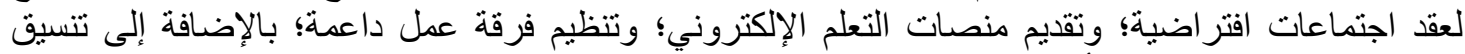

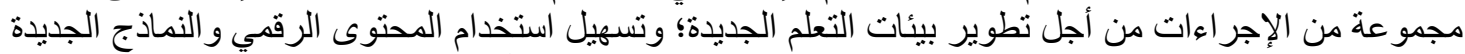

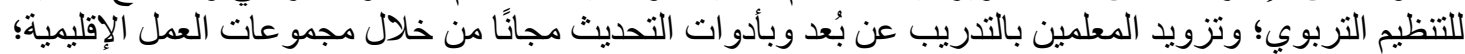

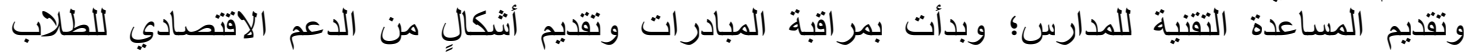
المحرومين اجتماعيًا و اقتصاديًا.

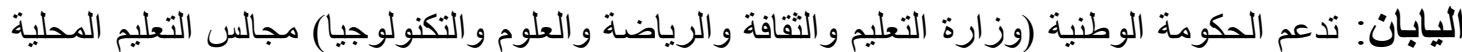

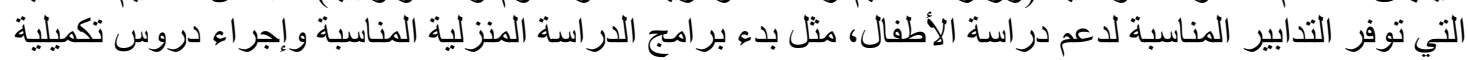

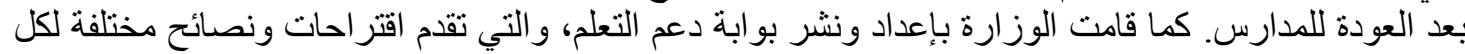




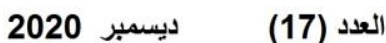

ISSN: 2415 - 4822
Volume (17) December 2020

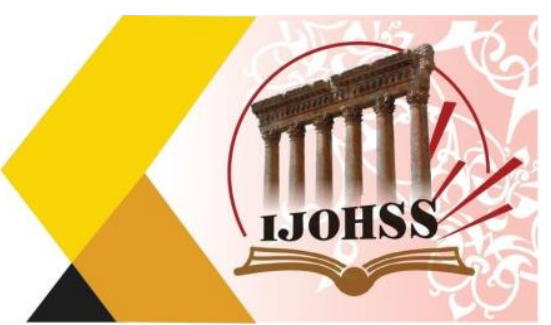

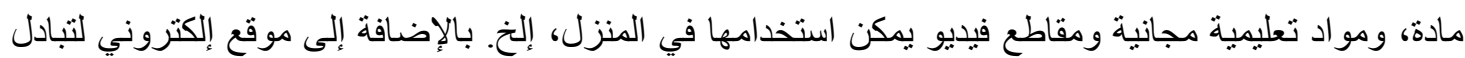

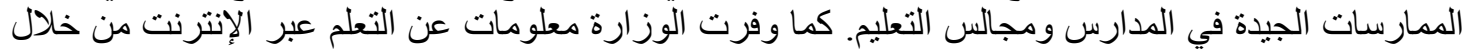
موقعها على الويب.

جمهورية لاتفيا: قام المركز الوطني للتعليم التابع لوزارة التربية والتعليم والعلوم بتطوير المبادئ التوجيهية التوبية

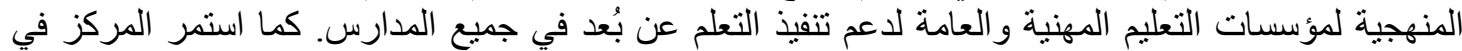

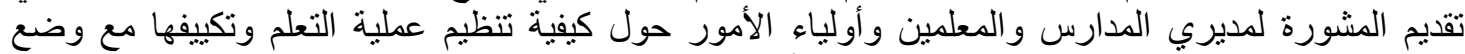

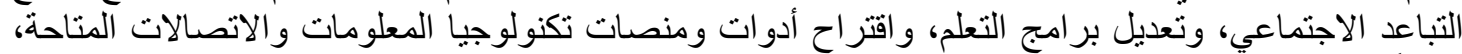

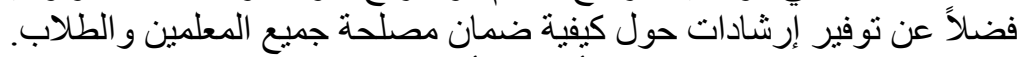

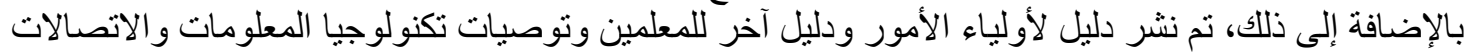

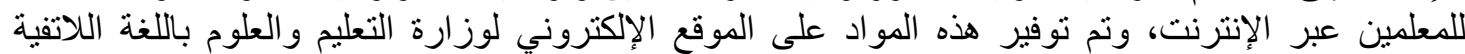

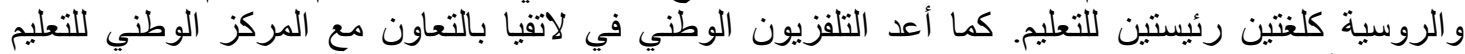

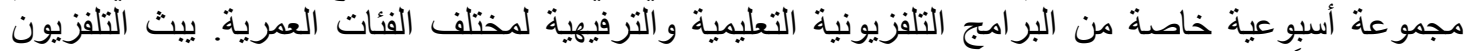

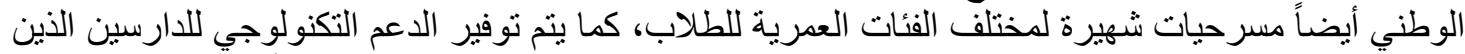

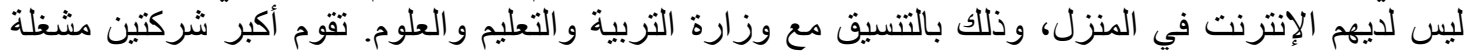

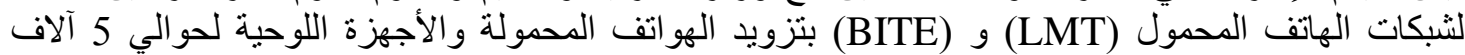

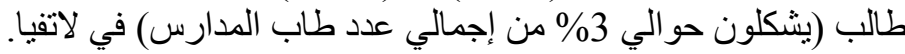

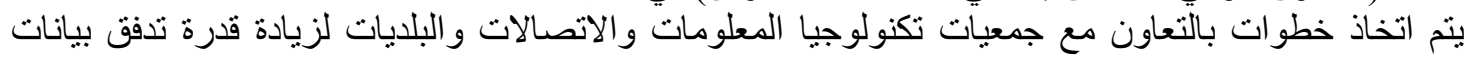

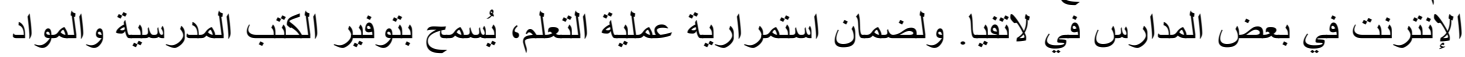

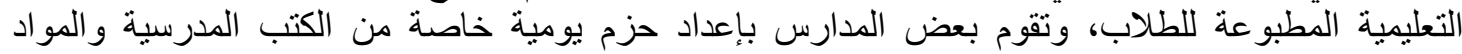
المطبو عة ليتم تسليمها للطلاب.

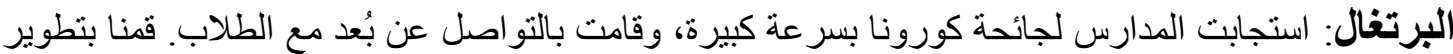

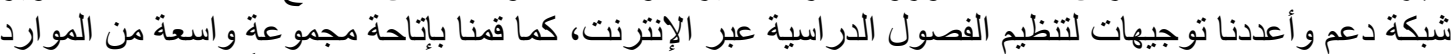

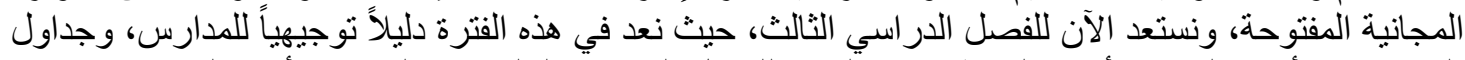

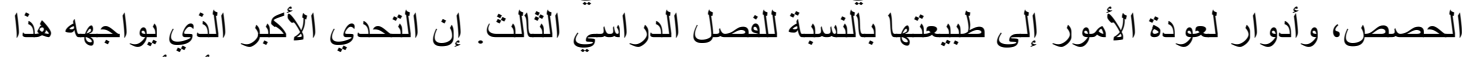

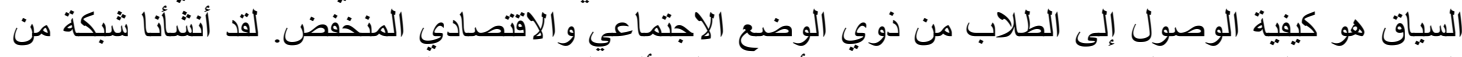

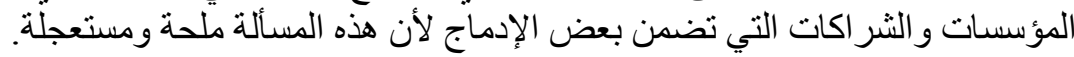

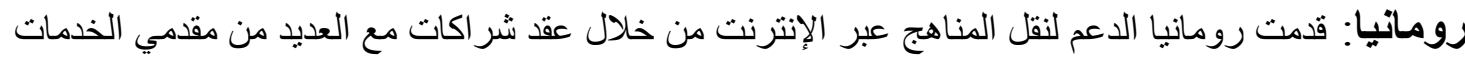

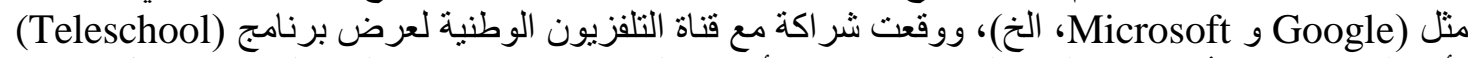

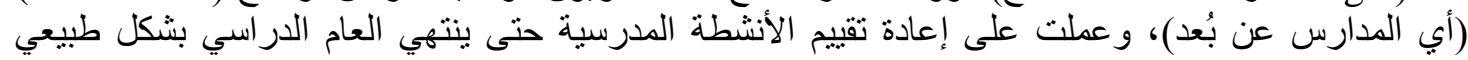

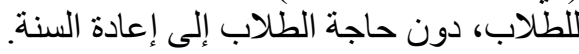
هولندا:

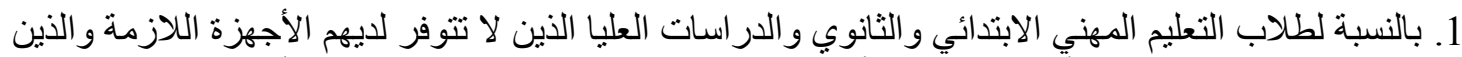

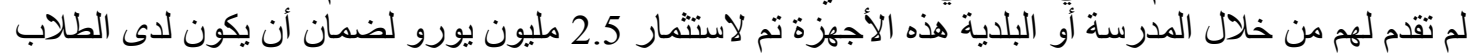
الأجهزة اللازمة للتعلم عبر الإنترنت التئ. 2. من الممكن أن تظل المدارس الإبتدائية و الثانوية مفتوحة بالنسبة للأطفال الذين يعمل و الديهم في وظائف مثل الصحة و الثرطة.

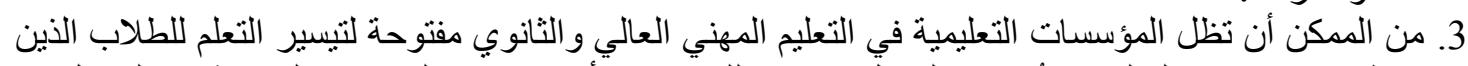

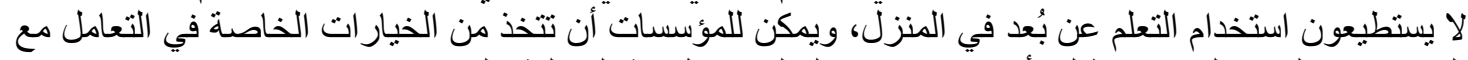

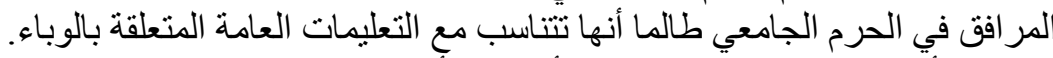

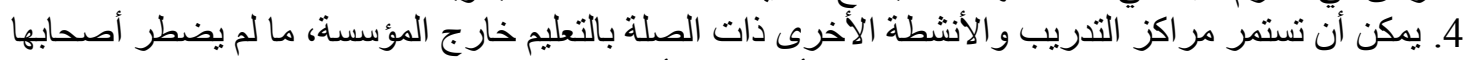

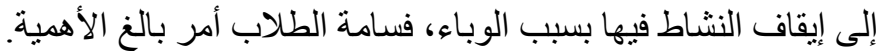

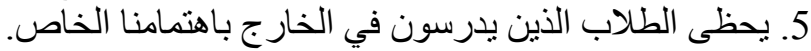




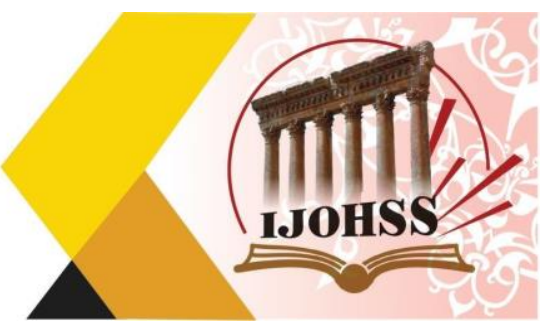

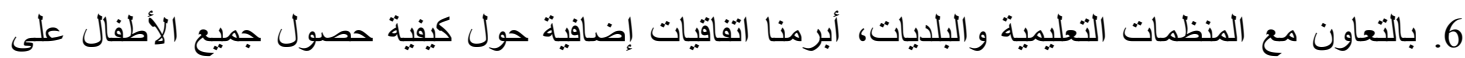

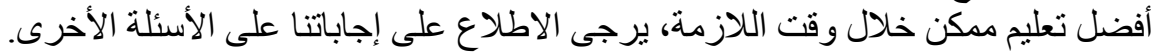

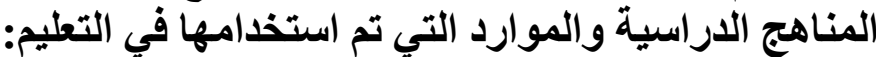

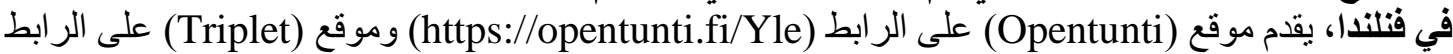

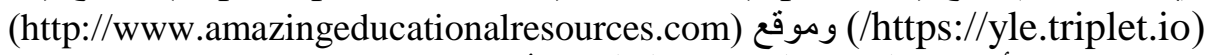

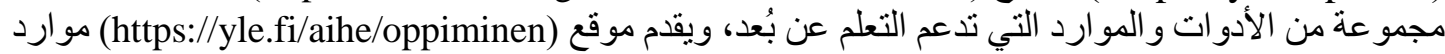

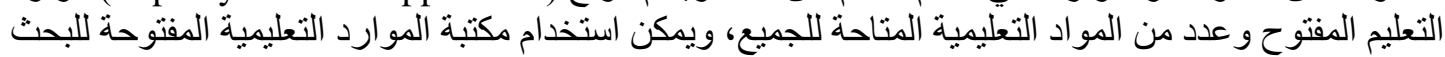
و إيجاد المصادر التعليمية المفتوحة وتجميعهاو ومشاركتها لجميع المر احل التعليمية على الر ابط التطاجئ .(https://aoe.fi/\#/etusivu) كما يقدم موقع (https://finna.fi) الذي ينضمن مجمو عة من المحفوظات و المكتبات و المتاحف الفنلندية عدداً

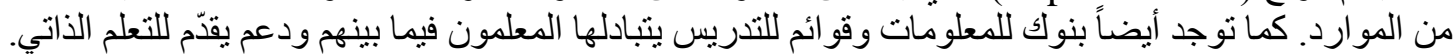

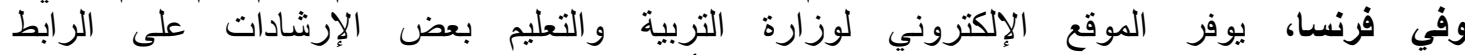
https://www.cned.fr/maclassealamaison

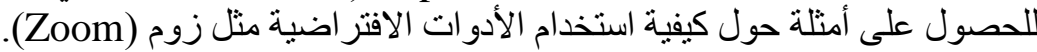
أما في اليابان، يقدم المعهد الوطني لمعلمي المدارس وتطولير الإدير الموظفين العديد من البرامج للمعلمين على الرابط (/https://www.nits.go.jp/en)

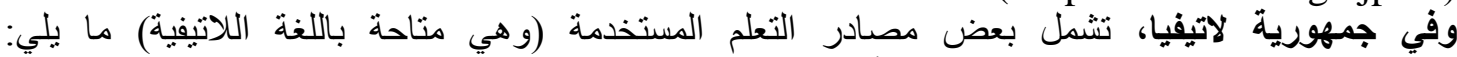

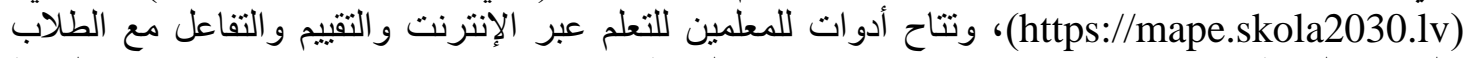

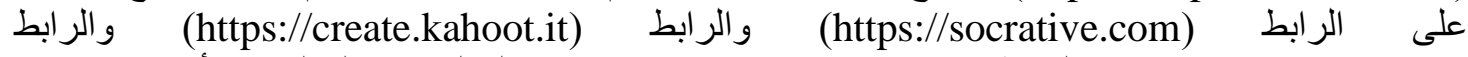

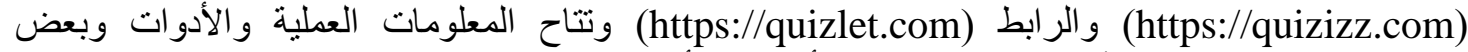

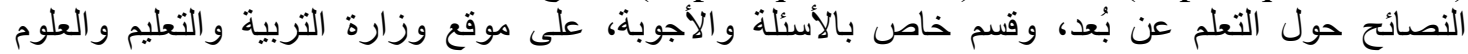
(https://www.izm.gov.lv/lv/macibas-attalinati) .(https://visc.gov.lv/aktualitates/info_20200318.shtml) المملكة العربية السعودية: تم توظيف التعليم عن بعد من خلال تقديم نوعين من التعليم:

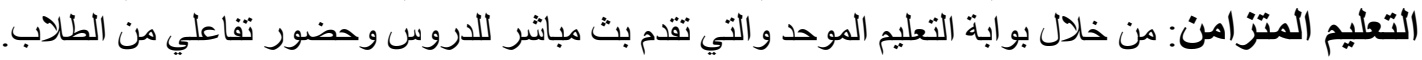

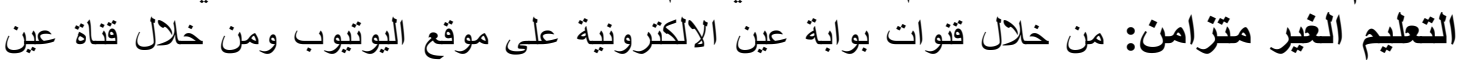
الفضائية في بث الديز مئز الدروس التعليمية.

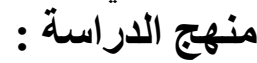
استخدم الباحث المنهج المسحي من خلال المسح المكتبي لأهم المو اقع و التقارير و الأبحاث و الدر اسات التي تناولت

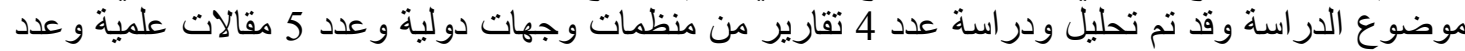

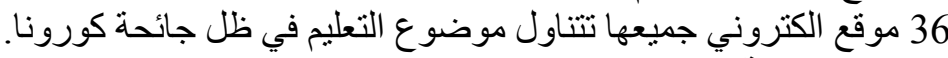

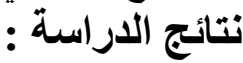

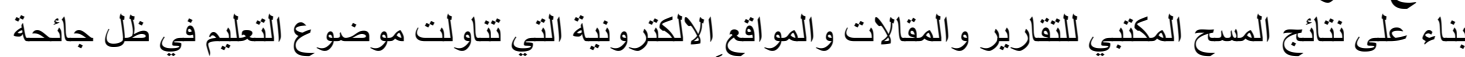
كورونا تم التوصل استنتاج عدد من التوصيات العلمية وفقاً لتجارب التابرت الدول في مجال التعليم في ظل جائحة كورونا وكانت مرتبة على النحو الآتي:

1. إنشاء فريق عمل أو لجنة توجيهية تكون مسؤولة عن تطوير وتنفيذ الاستجابة التعليمية لوباء فيروس كورونا

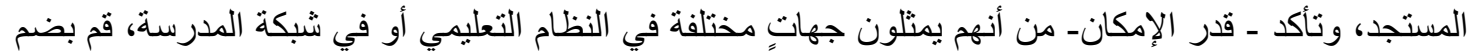

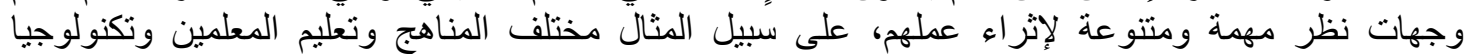

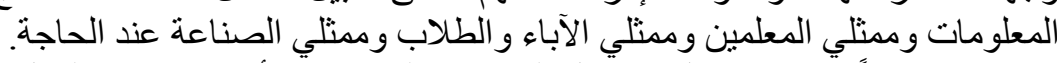

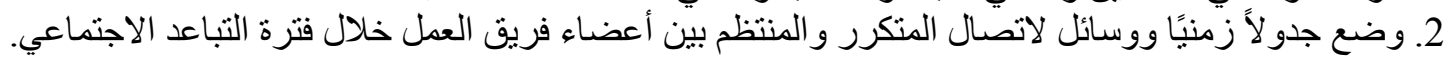




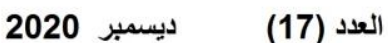

ISSN: 2415 - 4822

\section{Volume (17) December 2020}

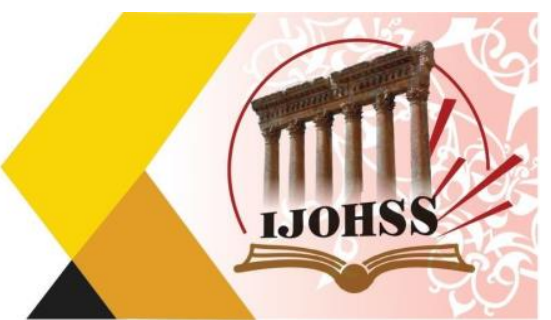

3. تحديد المبادئ التي سنوجه الاستر اتيجية. على سبيل المثال: حماية صحة الطلاب و الموظفين، وضمان التئية التعلم

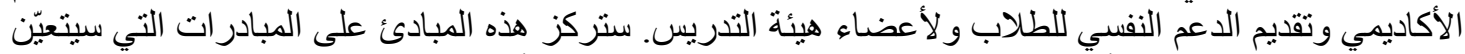

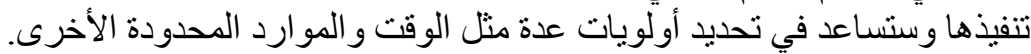

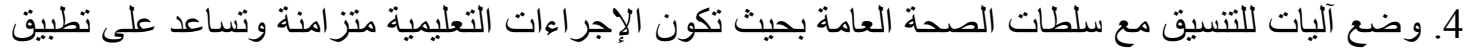

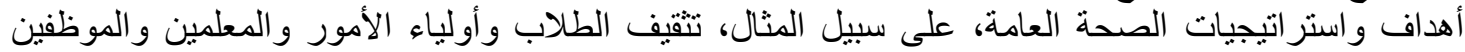
حول ضرورة التباعد الاجتماعي. 5. ترتيب أولويات أهداف المناهج بالنظر إلى حقيقة أن الأساليب المعتادة لثر ح الدروس غير قابلة للتطبيق. حدد ما يجب تعلمه خلال فترة التباعد الاجتماعي.

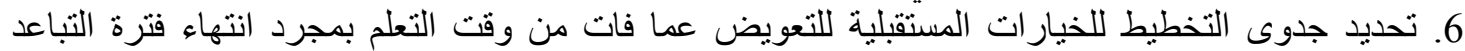

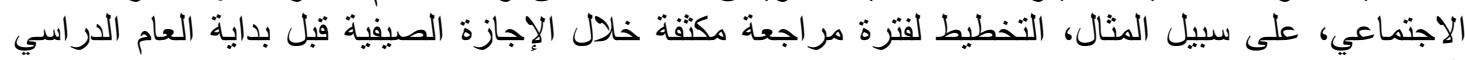
الجديد.

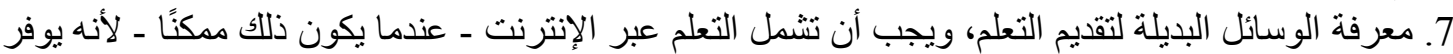

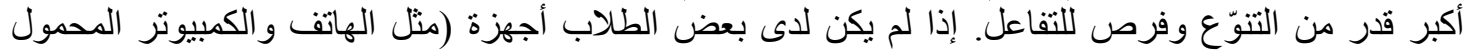

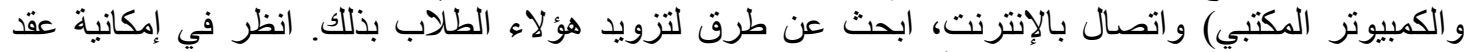

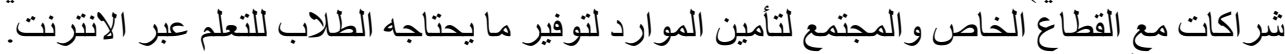

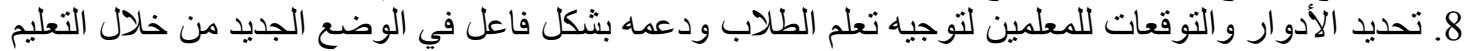
المباشر حيثما أمكن أو التوجيه للتعلم الذاتي.

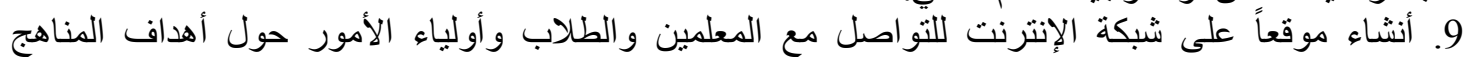

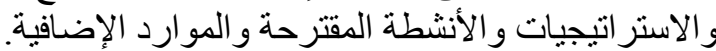

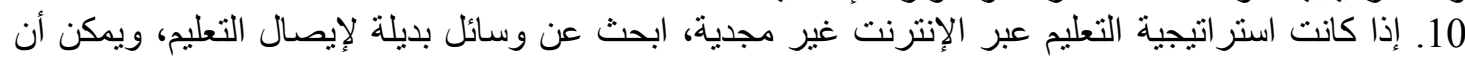

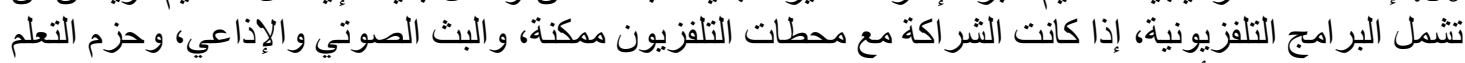
إما في شكل رقمي أو على الورق. انظر في إمكانية عقد شر اكات مع منظمات المجتمع و القطاع الخاص التهاع التقديم

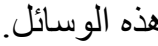
11. التأكد من وجود الدعم الكافي للطلاب و الأسر الأكثر ضعفًا خلال تتفيذ خطة التعليم البديل

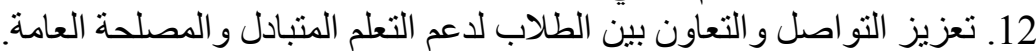

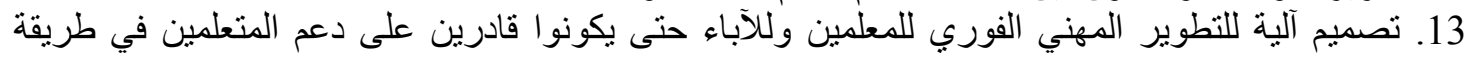

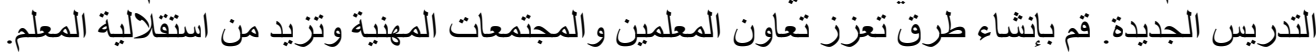

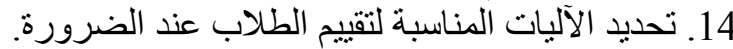

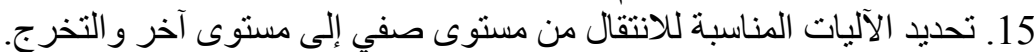

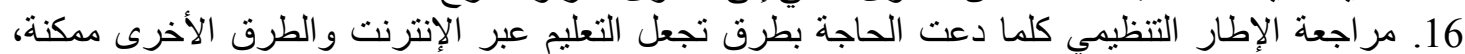

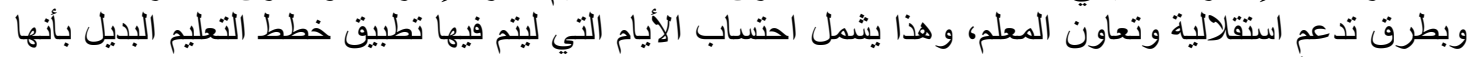
من رصيد الأيام المدرسية العادية. 17. يجب على كلى كلى مدرسة وضع خطة لاستمرارية التعليم. كوسيلة للاعم، يمكن للسلطات التعليمية تقديم أمثلة

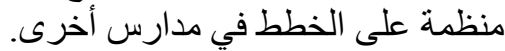
18. إذا كانت المدرسة تقدم وجبات غذائية للطلاب، قم بتطوير وسائل بديلة لتوزيع الطعام على الطلاب و أسرهم.

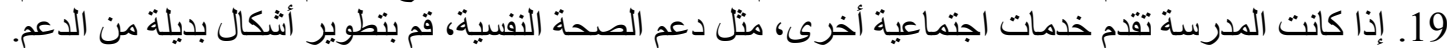

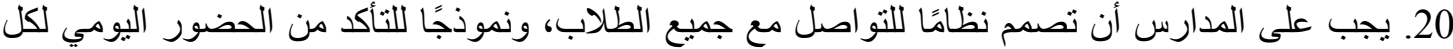

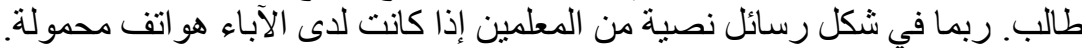

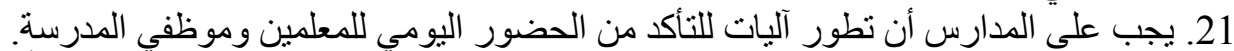

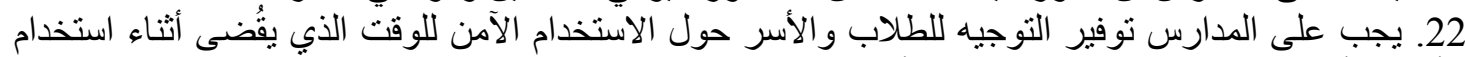

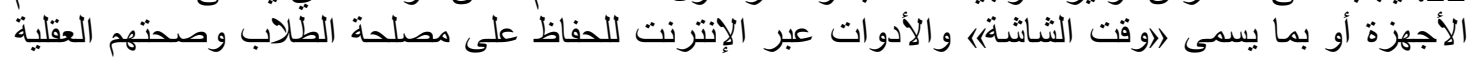

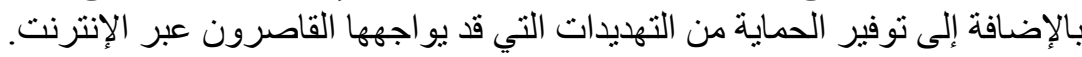


العدد (17) (17) Volume (17) December 2020

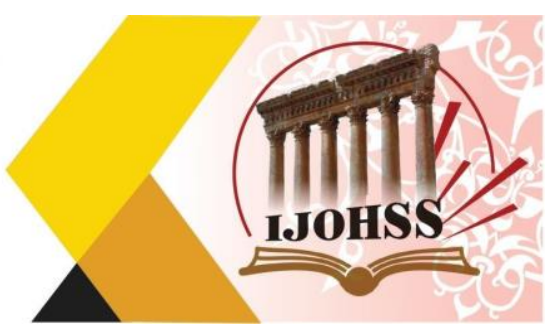

23. اختر شبكات أو أنظمة مدرسية أخرى و أنشئ شكلاً من أثنكال التو اصل المنتظم معها لتبادل المعلومات حول

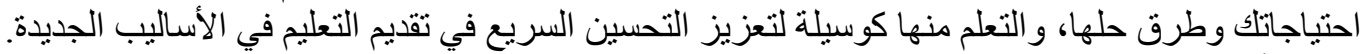

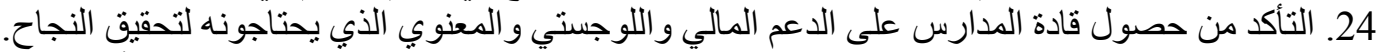

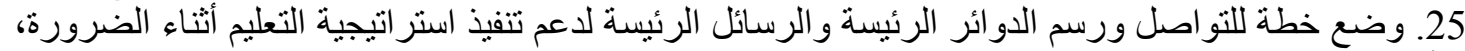

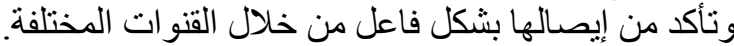
ترتيب التوصيات ذات الأولوية بحسب البلان التان:

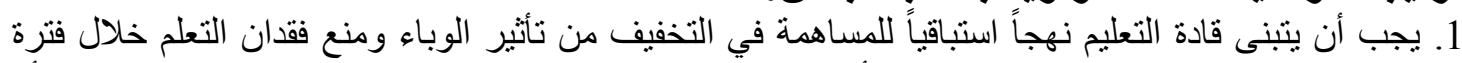

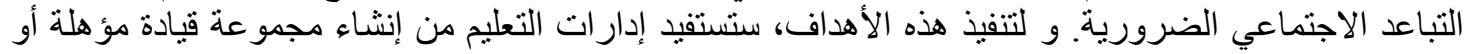

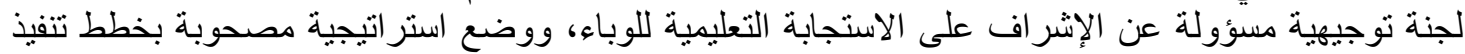

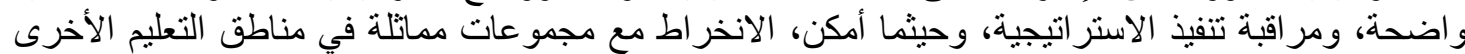

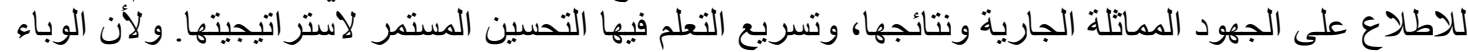

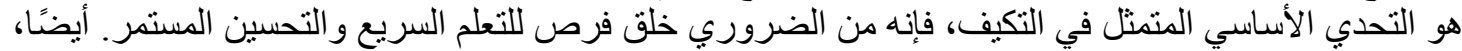

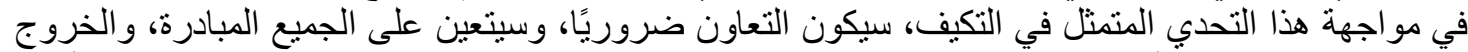

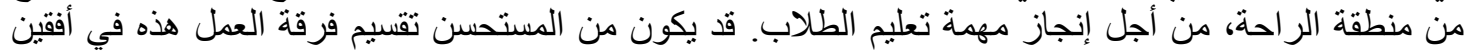

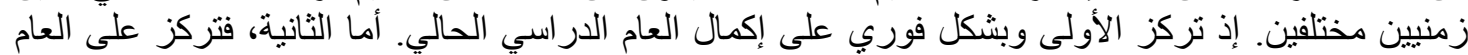

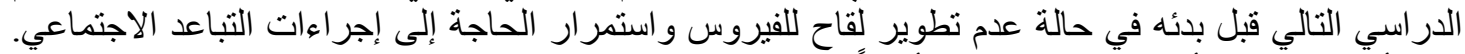

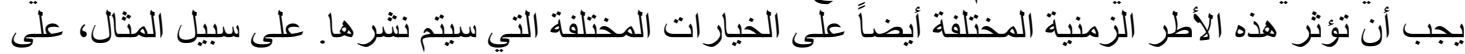

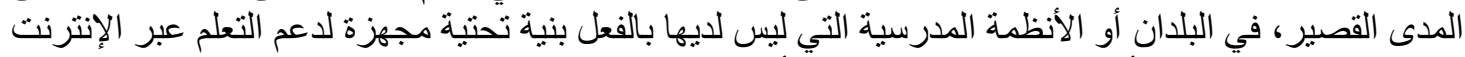

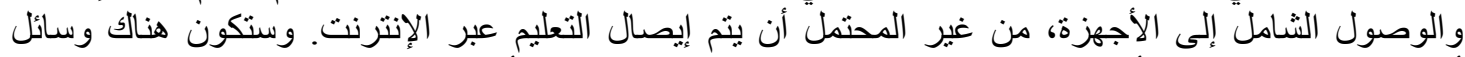

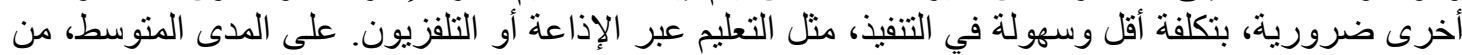
المكن توفير البنية التحتية للتعلم عبر الإنترنت، و هو استثمار من المرجح أن يعود بالنفع و الفائدة على تلألك البلدان بعد أن تتجاوز الجائحة الحالية.

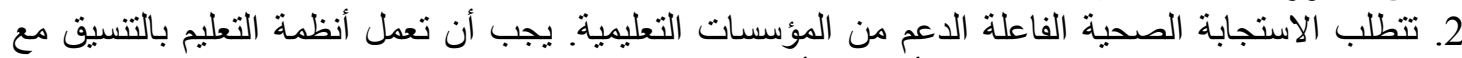

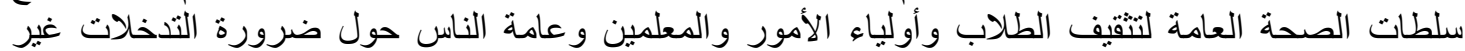

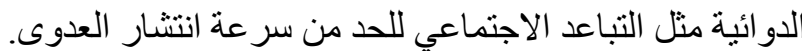

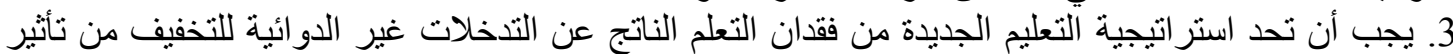

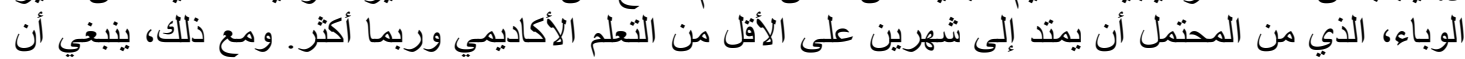

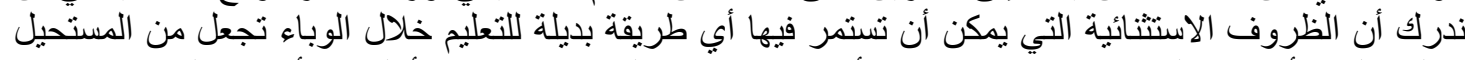

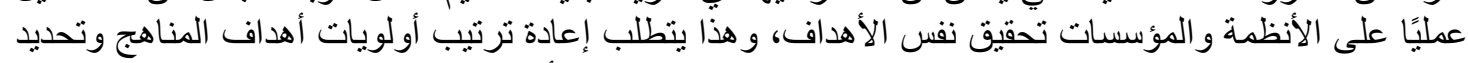

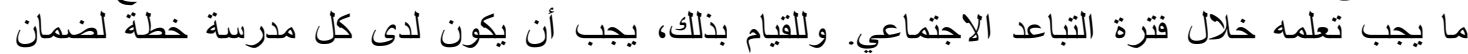

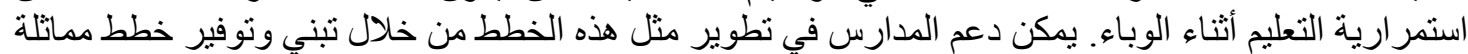

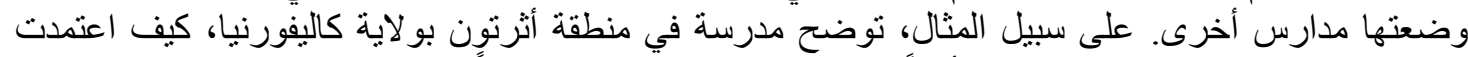

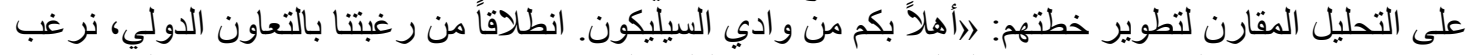

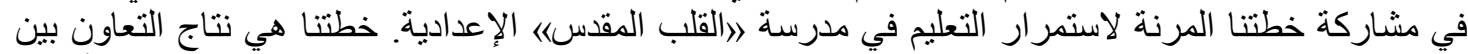

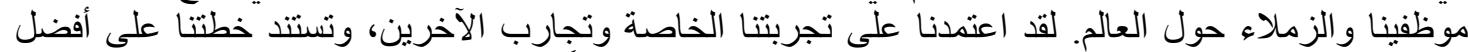

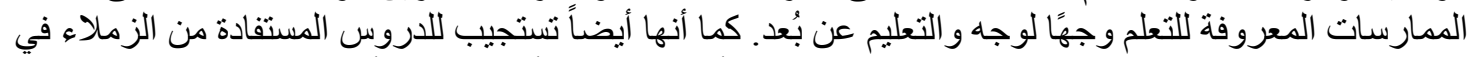

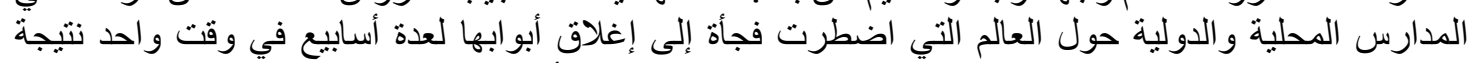

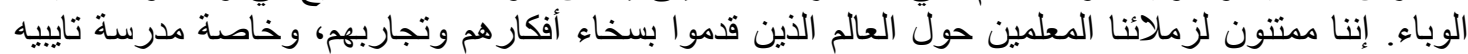

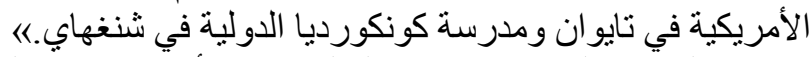

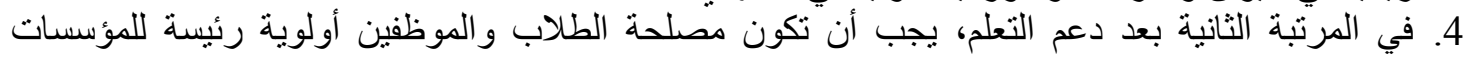

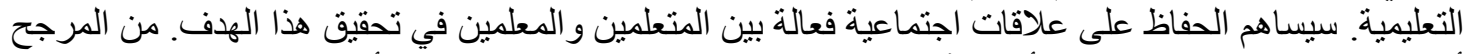

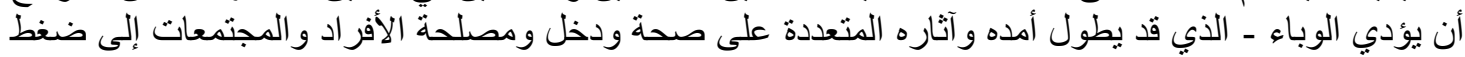




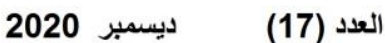

ISSN: $2415-4822$
Volume (17) December 2020

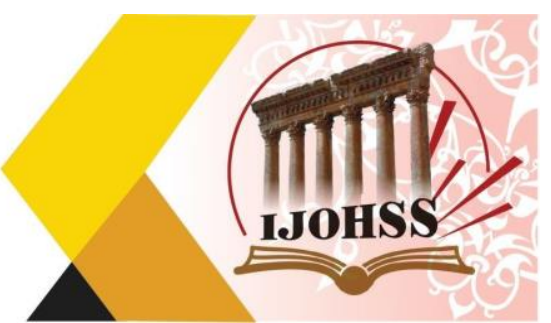

نفسي على الجميع، بما في ذلك الطلاب و المعلمين. و لأجل ذللك، ينبغي على معلمي وقادة أنظمة التعليم أن يحددوا

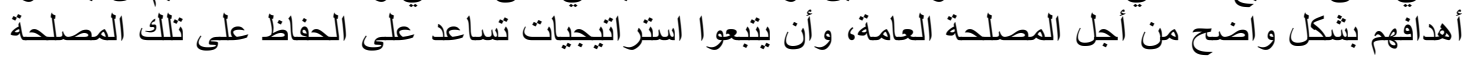

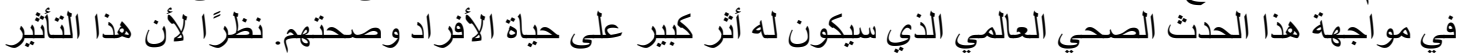

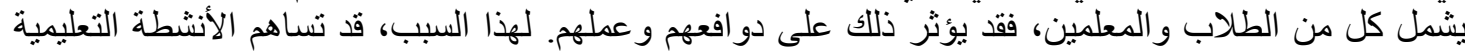

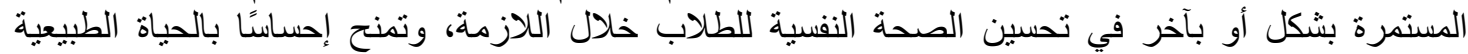

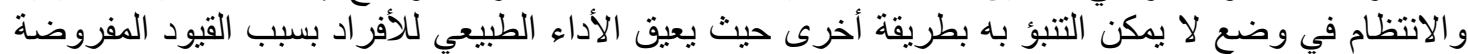

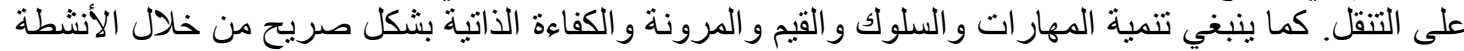

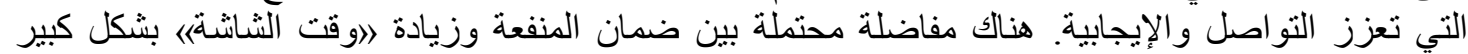

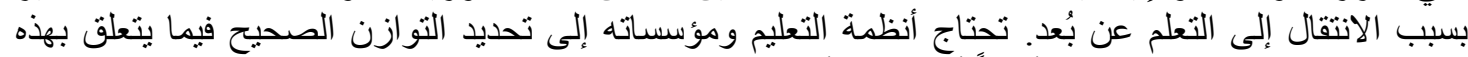

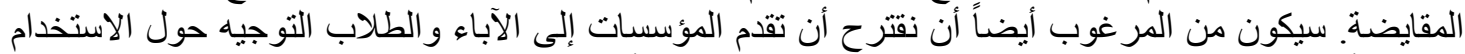

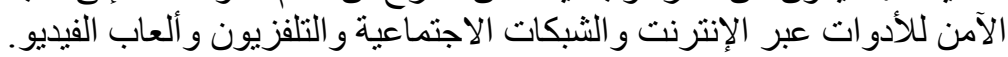

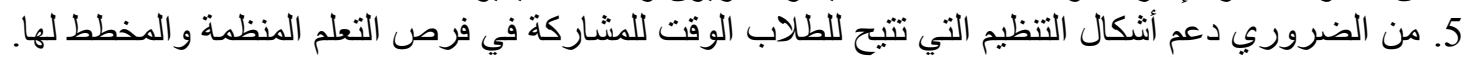

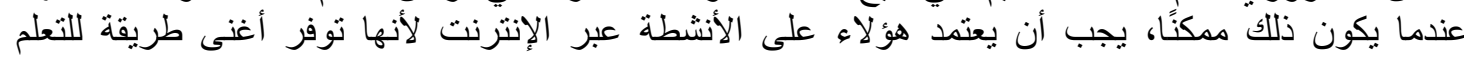

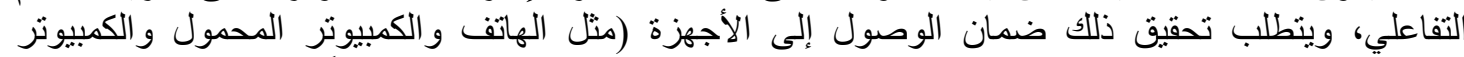

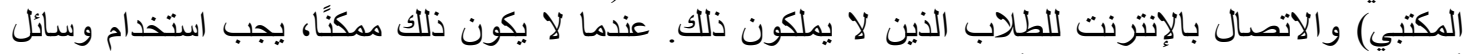

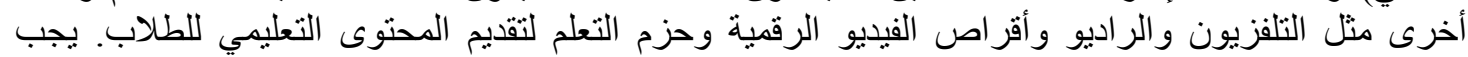

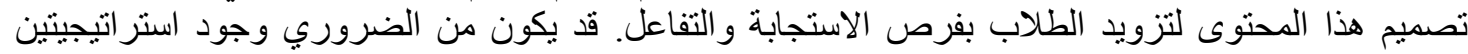

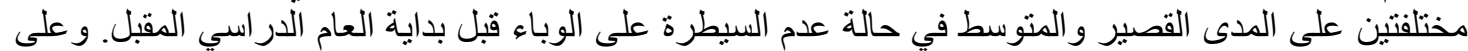

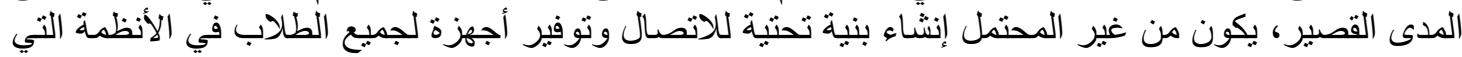

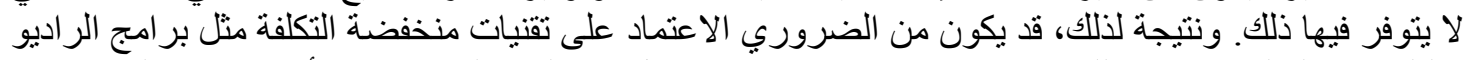

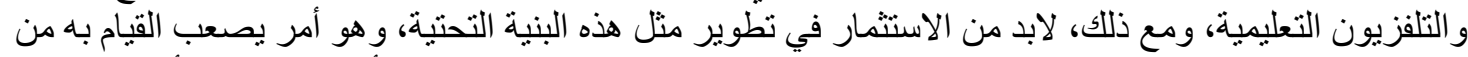

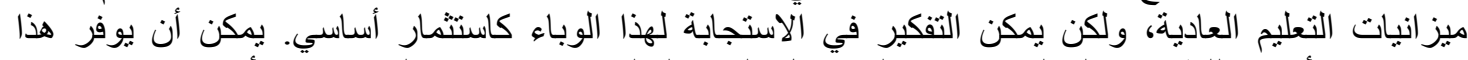

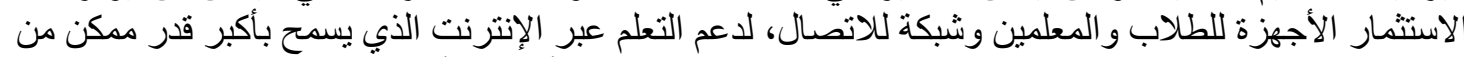

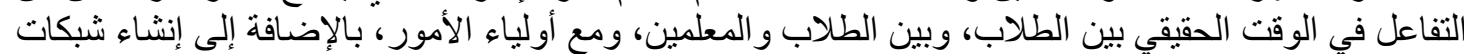

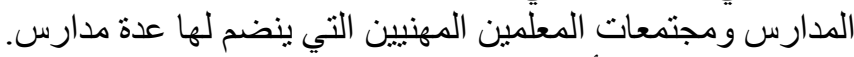

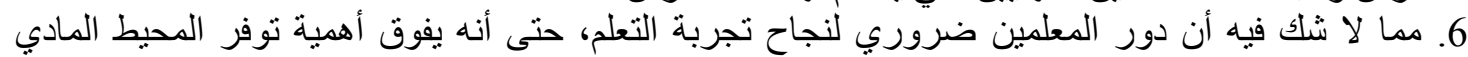

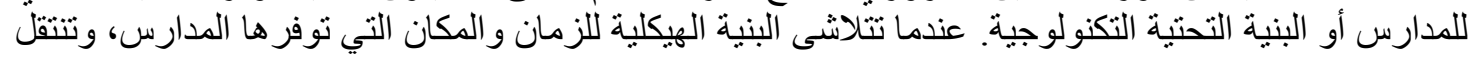

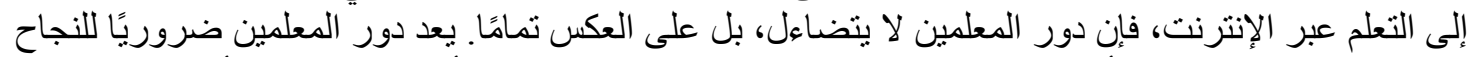

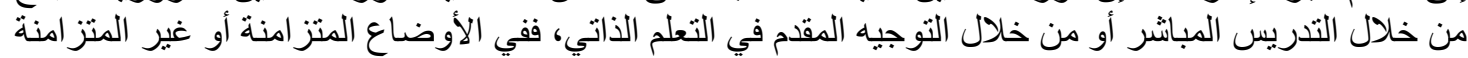

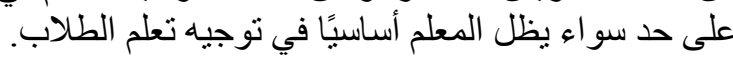

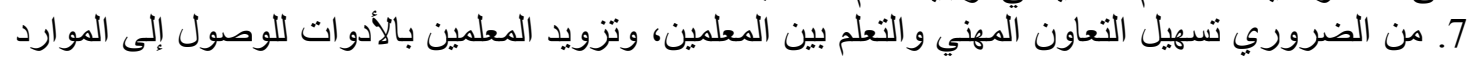

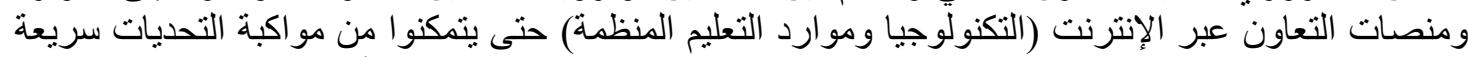

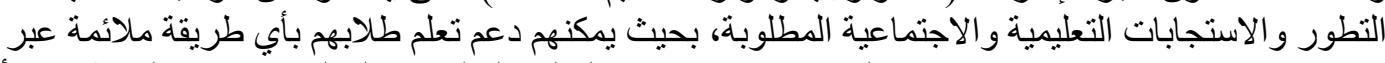

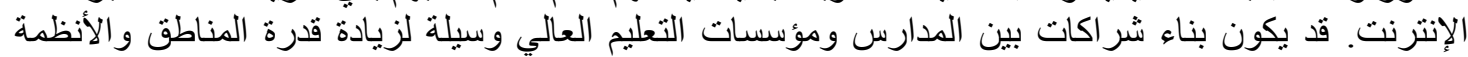

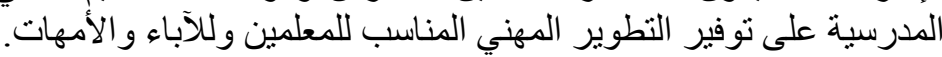

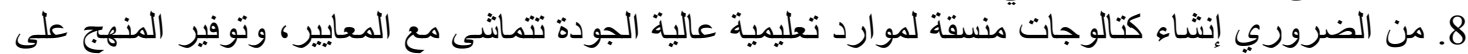

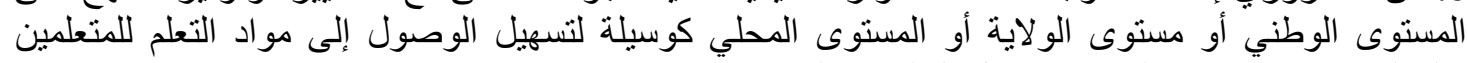

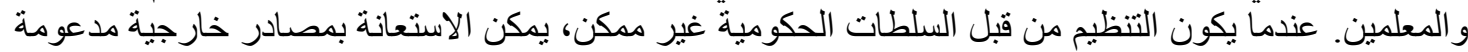

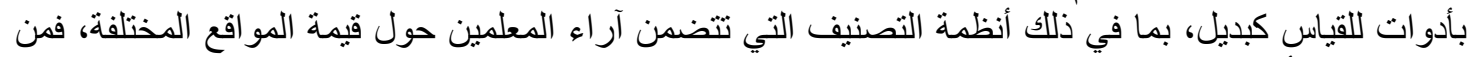

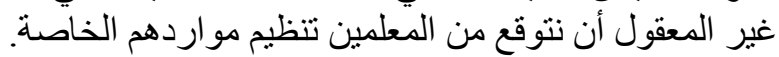

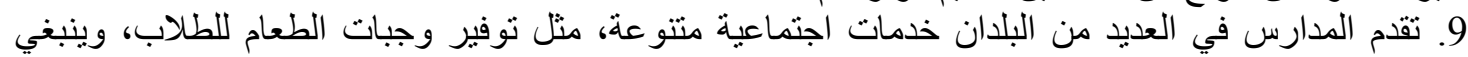

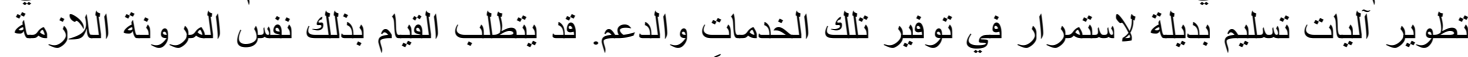
لاعم الردود المبتكرة والمقترحة ، على سبيل المثال، بدلاً من تقديم الوجبات، والتيل والتي قد تكون معقدة من الناحية 


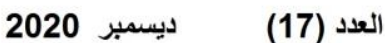

ISSN: 2415 - 4822
Volume (17) December 2020

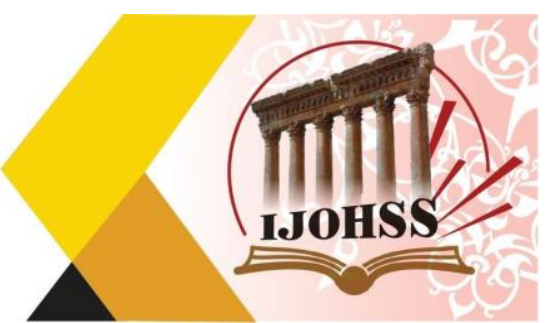

اللوجستية، قد يكون من الممكن تحويل مبالغ مالية للعائلات باستخدام النظام المصرفي أكثر فعالية، ويجب بذل كل

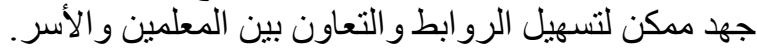

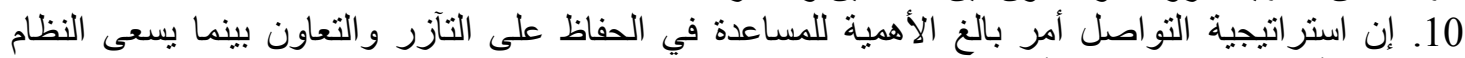

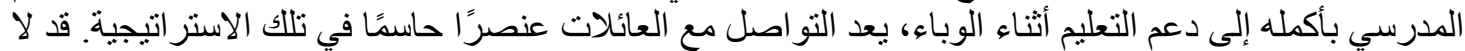

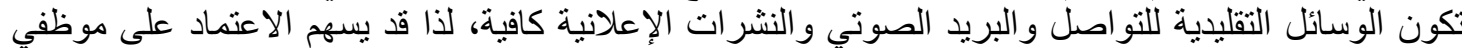

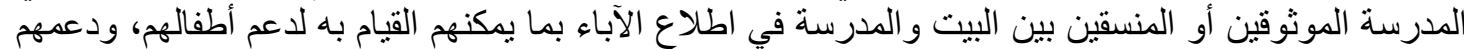
أثناء القيام بذلك.

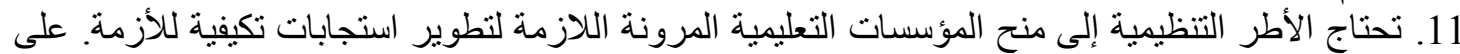

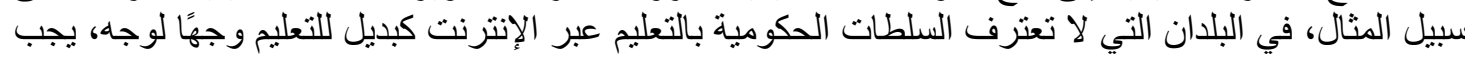

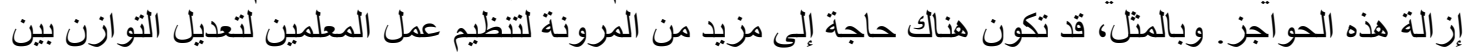

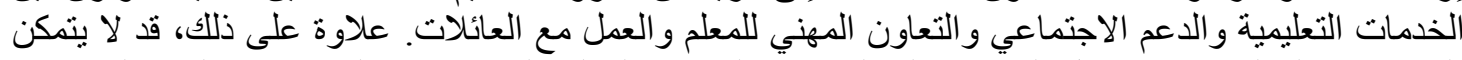

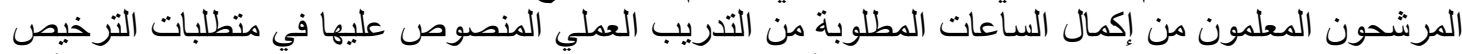

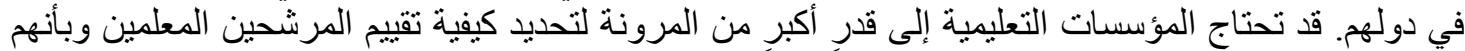

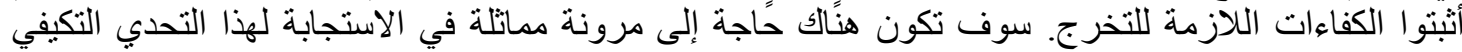

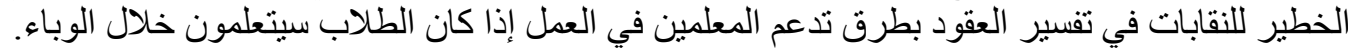

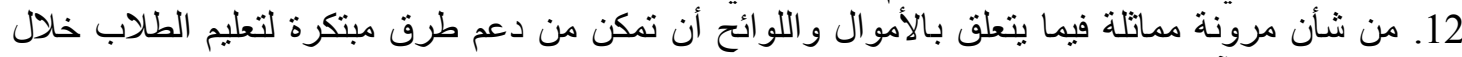

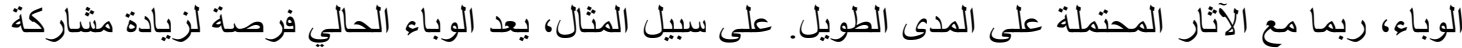

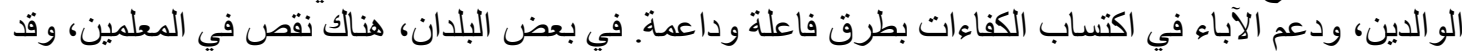

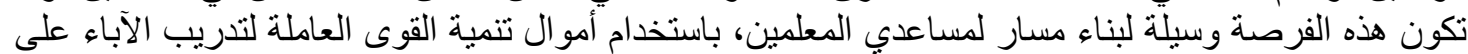

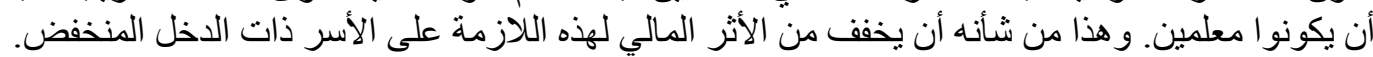

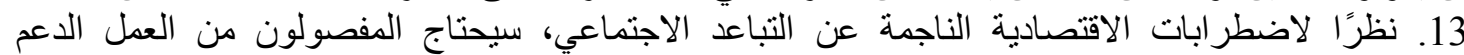

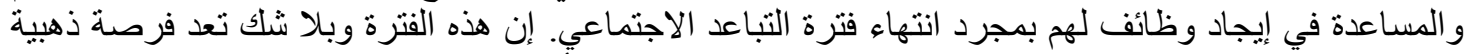

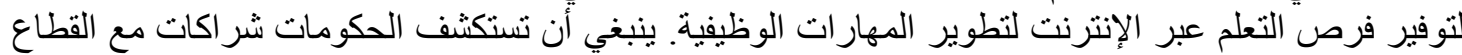
الخاص لتوسيع نطاق تو افر تللك الفرص من خلال الإنترنت أو طر ائق مماثلة أثناء الحاجة الماسة إليها.

\section{توصيات عودة الطلاب للمدرسة}

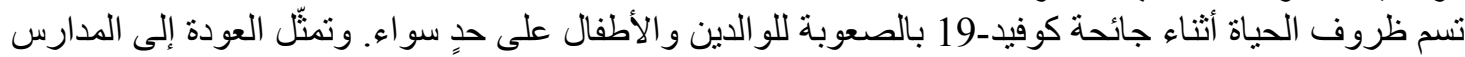

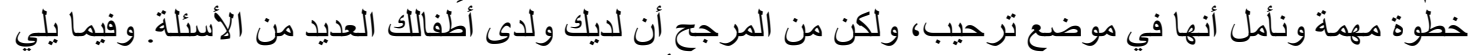

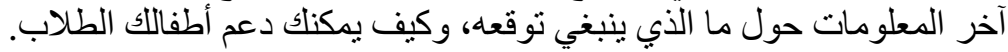

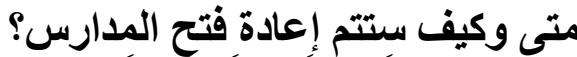

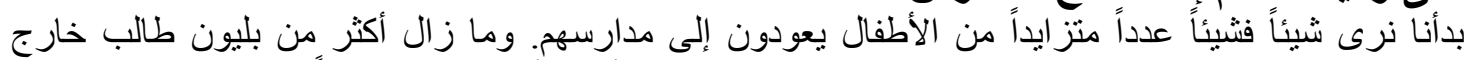

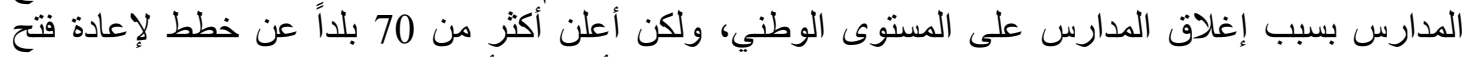

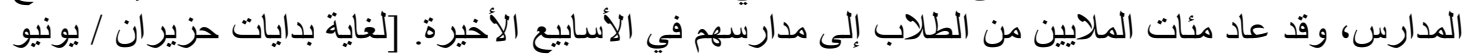

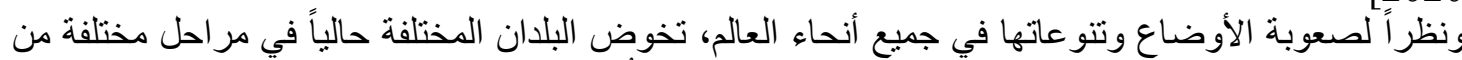

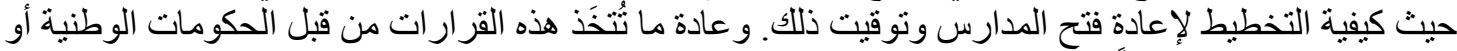

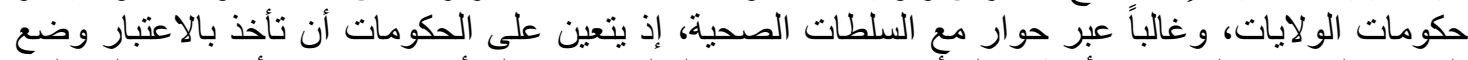

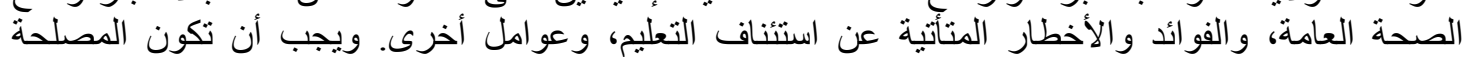

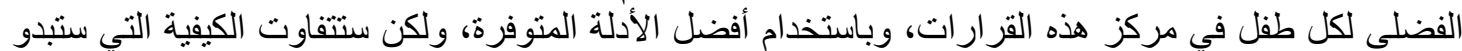
عليها هذه العملية بين مدرسة و وأخرى. 


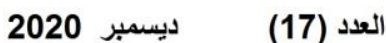

ISSN: 2415 - 4822

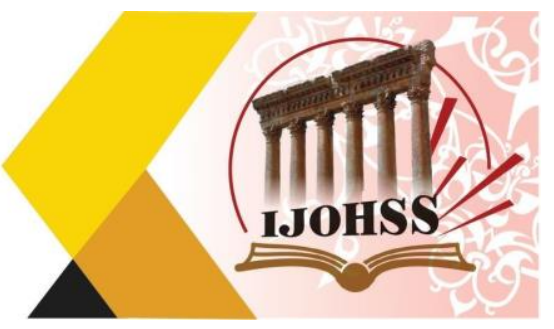

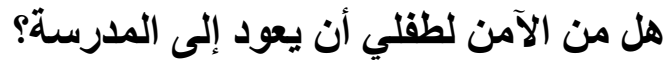

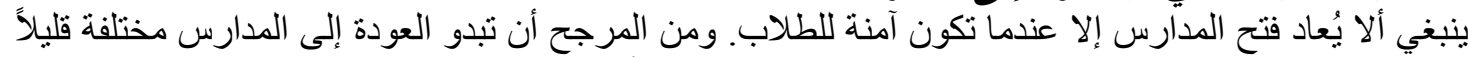

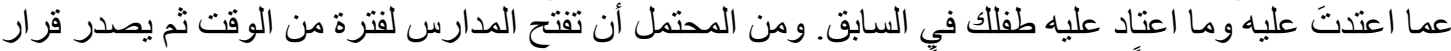

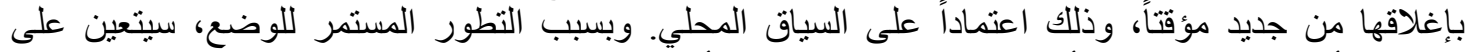

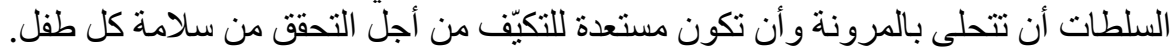

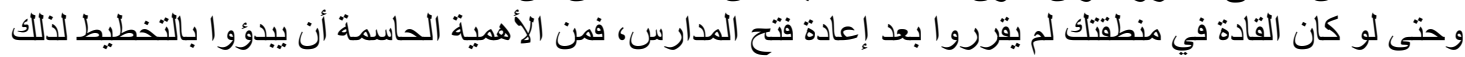

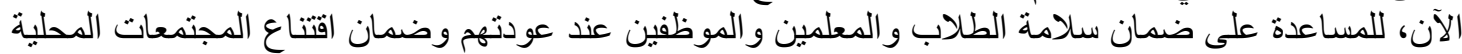

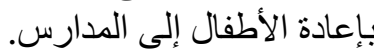

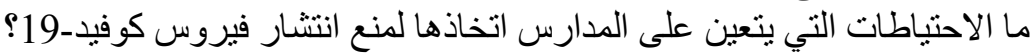
يجب أن تكون إعادة فتح المدارس متسقة مع الاستجابة الصحية العامة لكوفيد-19 في البلد المعني، وذلكارئ لحماية

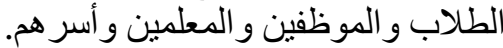

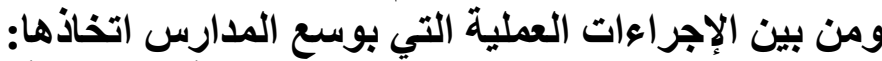

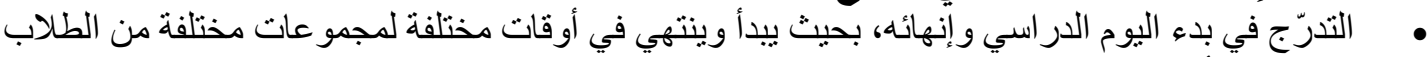

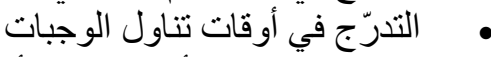

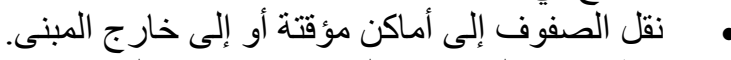

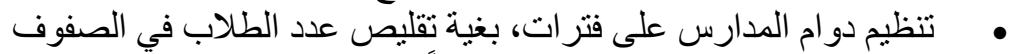

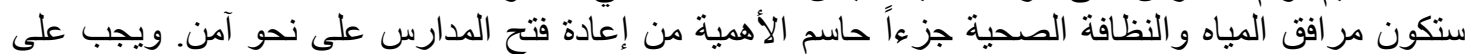

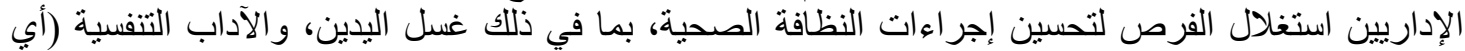

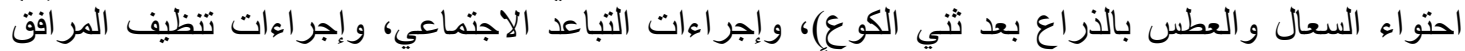

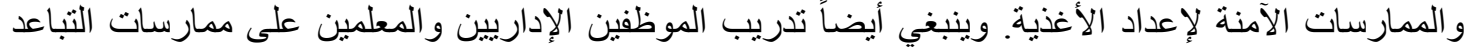

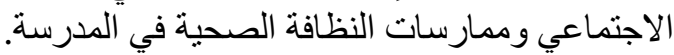

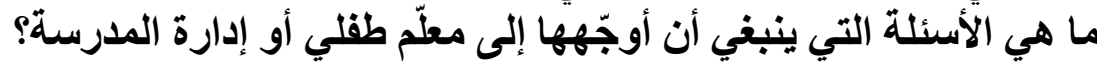

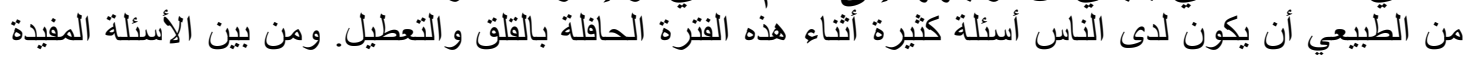

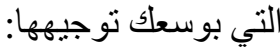

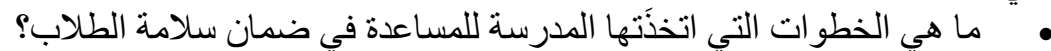

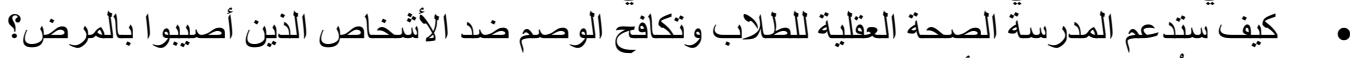

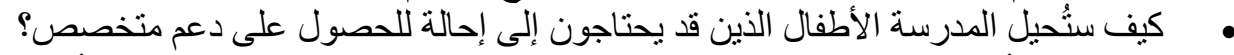

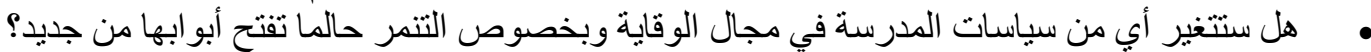

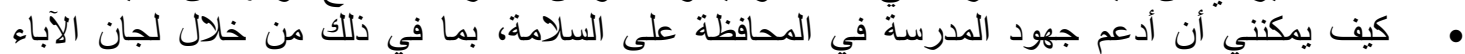

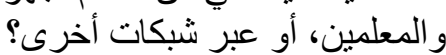

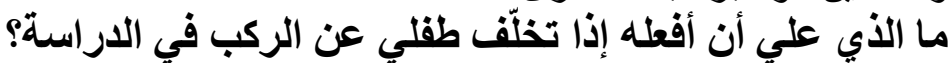

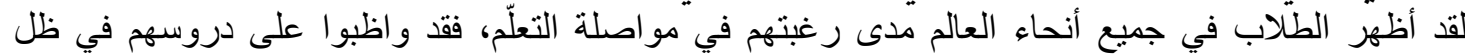

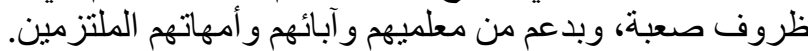

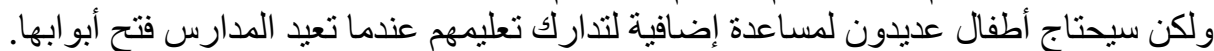

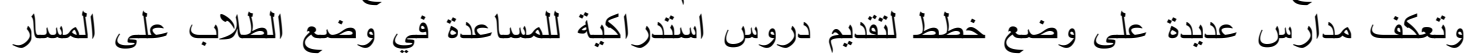

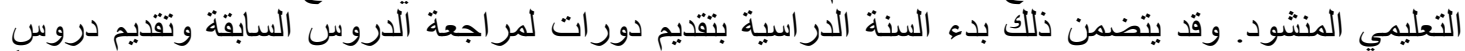

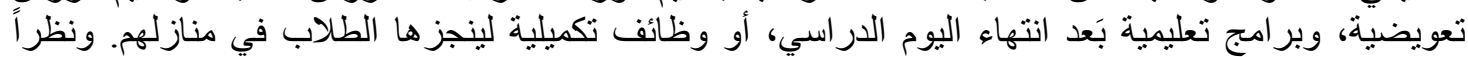

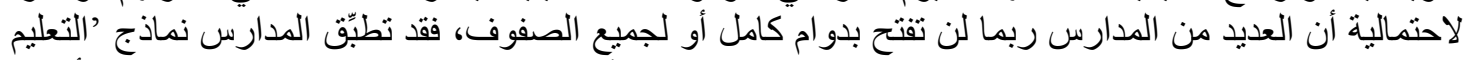

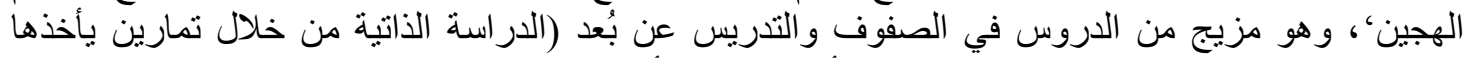

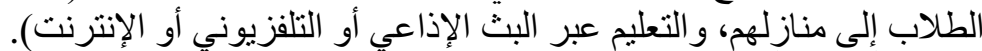

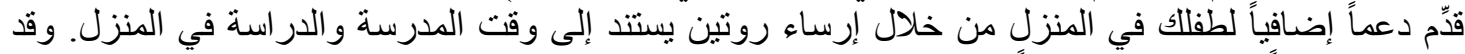
يكون ذلك مفيداً للطفل إذا كان بَرِماً ويو اجه صعوبة فئة في التركيز. 


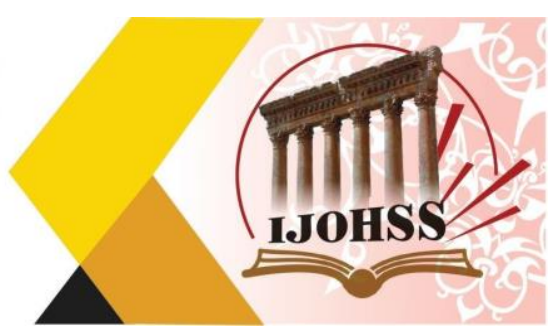

وقد تريد التو اصل مع معلّم طفلك أو مع المدرسة لتوجيه أسئلة لتظل مطلعاً على ما يجري. وتأكد من إبلاغهم إذا إذا إنها

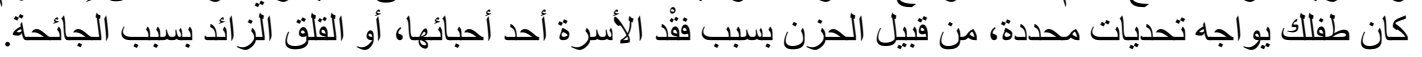

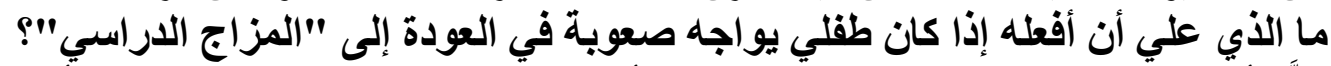

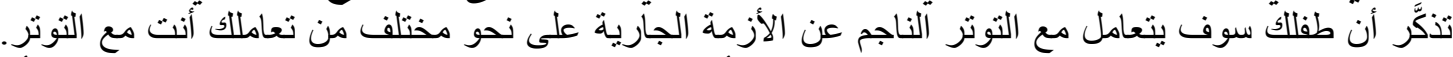

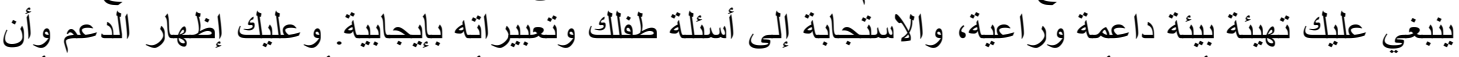

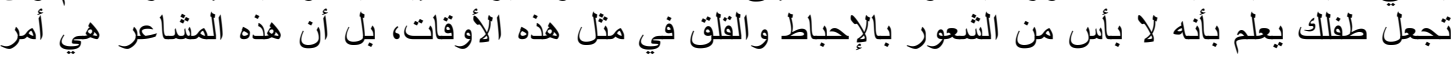

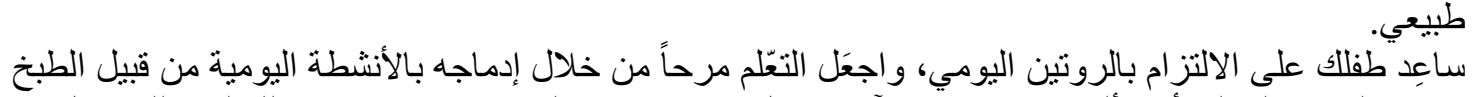

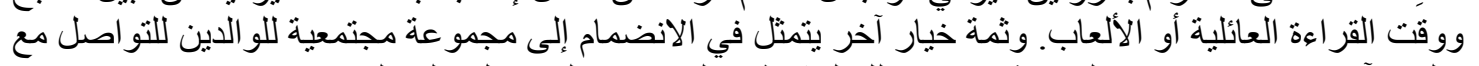

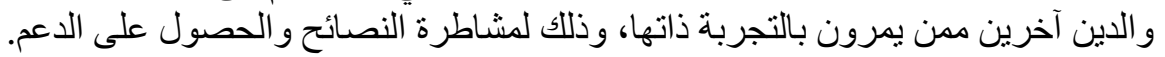

$$
\begin{aligned}
& \text { المراجع } \\
& \text { 1- تقرير منظمة التعاون الاقتصادي و التتمية (oecd) بعنو ان إطار عمل لتوجيه استجابة التعليم تجاه جائحة }
\end{aligned}
$$

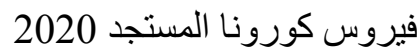

$$
\begin{aligned}
& \text { 2- تقرير توصيات منظمة اليونسيف كيف ستكون العودة للمدرسة على الر ابط: } \\
& \text { /https://www.unicef.org/ar } \\
& \text { 3- ثقرير مبادرة الألسكو للتعليم الالكتروني لمجابهة انقطاع التعليم بسبب أزمة كورونا: }
\end{aligned}
$$

1. https://ar.wikipedia.org/wiki/\%D8\%A3\%D8\%AB\%D8\%B1_\%D8\%AC\%D8\%A7\%D8\% A6\%D8\%AD\%D8\%A9_\%D9\%81\%D9\%8A\%D8\%B1\%D9\%88\%D8\%B3_\%D9\%83\%D9\%8 8\%D8\%B1\%D9\%88\%D9\%86\%D8\%A7_\%D8\%B9\%D9\%84\%D9\%89_\%D8\%A7\%D9\%84 \%D8\%AA\%D8\%B9\%D9\%84\%D9\%8A\%D9\%85_2019-20

2. https://www.alfanarmedia.org/ar/2020/05/\%D9\%85\%D8\%B3\%D8\%AA\%D9\%82\%D8\% A8\%D9\%84\%D8\%A7\%D9\%84\%D8\%AA\%D8\%B9\%D9\%84\%D9\%8A\%D9\%85\%D8\%A7 \%D9\%84\%D8\%B9\%D8\%A7\%D9\%84\%D9\%8A\%D9\%81\%D9\%8A\%D8\%B1\%D9\%88\%D 8\%B3\%D9\%83\%D9\%88\%D8\%B1\%D9\%88\%D9\%86\%D8\%A7/

3. https://blogs.worldbank.org/ar/education/educational-challenges-and-opportunities-covid19-pandemic

4. https://www.aleqt.com/2020/04/05/article_1797576.html

5. https://www.scientificamerican.com/arabic/articles/news/distance-learning-versuscovid19/

1. https://learning.careyinstitute.org/

$$
\text { 6- - - مواقع على شبكة الإنترنت }
$$

2. https://www.learninginpractice.org/movinglearningonline?preview=true

3. https://eduthek.at/schulmaterialiene-education.brac.net

4. www.techedu.gov.bd

5. https://www.klascement.net/thema/geen-les-opschool

6. www.mon.bg

7. https://play.google.com/store/apps/details?id=secondary.academy.miya\&hl=eneducarcchil e.cllearnenglishbritishcouncil 


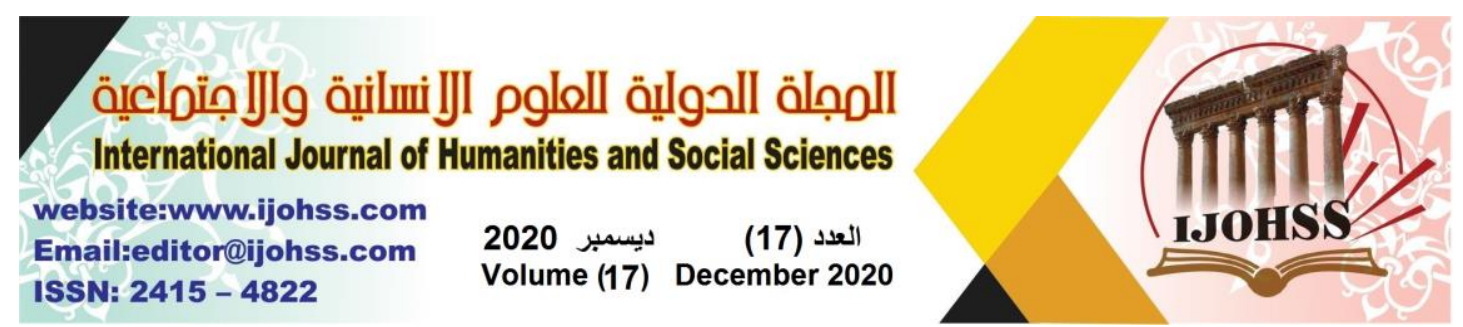

8. https://educationaboveall.org/\#!/news/eaaprovides-home-learning-support-for-parentsandguardians

9. https://hundred.org/en/articles/a-guide-for-caringfor-children-during-extended-familyconfinement

10. https://www.jenniferchangwathall.com/resources

11. https://www.mckinsey.com/business-functions/organization/our-insights/leadership-in-acrisisresponding-to-the-coronavirus-outbreak-andfuture-challenges?cid=otheremlaltmipmck\&hlkid=c253534b9ada4e3da6593104054fe111\&hctky=9652078\&hdpid=16a43 b5b-480b-4b3b-b8cf-bc20fcc11b08\#

12. https://www.cois.org/about-cis/perspectivesblog/blog-post/ board/perspectivesblog/post/managing-ambiguity-a-competency-to-harness-nowand-for-the-future

13. http://1s1k.eduyun.cn/

14. www.alianzaeducativa.edu.co

15. https://micuentofantastico.cr/recursos

16. https://micuentofantastico.cr/coleccion-fantastica/

17. https://cajadeherramientas.mep.go.cr/

18. https://nadalku.msmt.cz/cs

19. www.televisioneducativa.gob.mx

20. https://www.esl-lab.com/

21. Hitsa.ee

22. https://www.hm.ee/et/koroonaviiruse-levikutokestamine-info-haridusasutustele

23. https://www.hitsa.ee/e-ope-korduma-kippuvadkusimused

24. https://www.facebook.com/groups/278900333094971/?ref=group_headerâc€

25. https://www.innove.ee/uudis/info-ja-nouandedvanematele-oma-lapse-toetamiseks-COVID-

19-pandeemia-ajal/

26. https://www.hitsa.ee/e-ope-korduma-kippuvadkusimused

27. www.innove.ee

28. www.hm.ee

29. www.hitsa.ee

30. https://minedu.fi/koronavirus-ja-varautuminen

31. www.continuitepedagogique.org

32. http://solidarite.edtechfrance.fr/

33. http://pronote. $0640055 \mathrm{~m}$. ac-bordeaux.fr/pronote/professeur.html?login=true

34. www.jobsandinternshipsabroad.com

35. unterricht.de؛

36. simpleclub.de 